\title{
Testing for Recurrence of Ratio-Strained Behavior with Reinstatement, Resurgence, and Renewal
}

\author{
Stephanie L. Kincaid
}

Follow this and additional works at: https://researchrepository.wvu.edu/etd

\section{Recommended Citation}

Kincaid, Stephanie L., "Testing for Recurrence of Ratio-Strained Behavior with Reinstatement, Resurgence, and Renewal" (2015). Graduate Theses, Dissertations, and Problem Reports. 5975.

https://researchrepository.wvu.edu/etd/5975

This Dissertation is protected by copyright and/or related rights. It has been brought to you by the The Research Repository @ WVU with permission from the rights-holder(s). You are free to use this Dissertation in any way that is permitted by the copyright and related rights legislation that applies to your use. For other uses you must obtain permission from the rights-holder(s) directly, unless additional rights are indicated by a Creative Commons license in the record and/ or on the work itself. This Dissertation has been accepted for inclusion in WVU Graduate Theses, Dissertations, and Problem Reports collection by an authorized administrator of The Research Repository @ WVU.

For more information, please contact researchrepository@mail.wvu.edu. 
Testing for Recurrence of Ratio-Strained Behavior with Reinstatement, Resurgence, and Renewal

\author{
Stephanie L. Kincaid \\ Dissertation submitted \\ to the Eberly College of Arts and Sciences \\ at West Virginia University \\ in partial fulfillment of the requirements for the degree of \\ Doctor of Philosophy in \\ Psychology: Behavior Analysis
}

Kennon A. Lattal, Ph.D., Chair

Michael Perone, Ph.D.

Karen G. Anderson, Ph.D.

Steven Kinsey, Ph.D.

Daniel Hursh, Ph.D.

Department of Psychology

Morgantown, West Virginia

2015

Keywords: Recurrence, Relapse, Reinforcement, Progressive Ratio, Pigeon

Copyright 2015 Stephanie L. Kincaid 


\section{ABSTRACT \\ Testing for Recurrence of Ratio-Strained Behavior with \\ Reinstatement, Resurgence, and Renewal \\ Stephanie L. Kincaid}

If more and more responding is required to earn a reinforcer, as in progressive ratio schedules, behavior eventually becomes "strained," characterized by long pauses and irregular response patterns. If the response requirement continues to escalate, behavior reaches a "break point" and ultimately ceases altogether for a period of time. The present experiments investigated whether responding can be regenerated after the break point has been reached, using techniques that are known to produce recurrence of behavior that was eliminated by extinction. Pigeons responded on progressive ratio schedules until stable performance was observed. Then, test sessions were conducted in which a recurrence procedure (reinstatement, renewal, or resurgence) was applied after the break point had been reached. All recurrence procedures regenerated responding, demonstrating that the same procedures known to produce recurrence of extinguished behavior also can produce recurrence of behavior eliminated by progressive-ratio schedules. 


\section{TABLE OF CONTENTS}

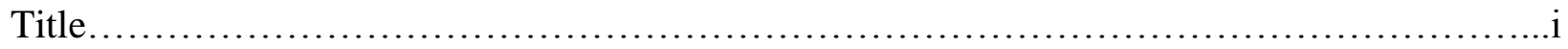

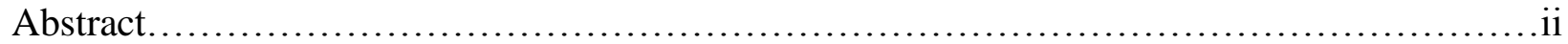

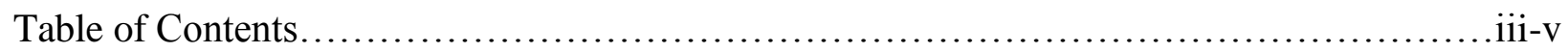

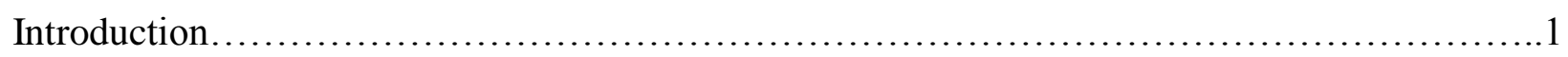

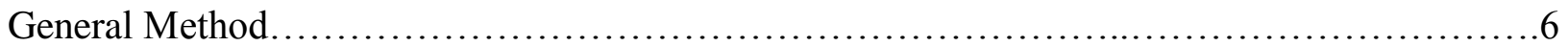

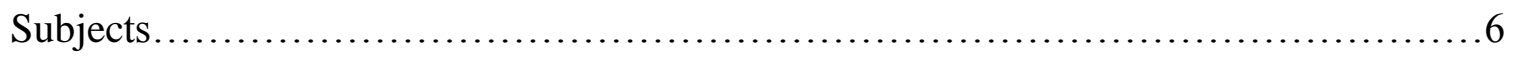

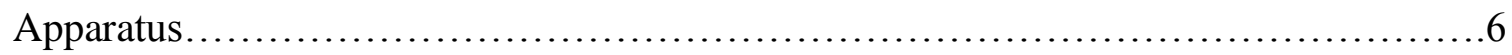

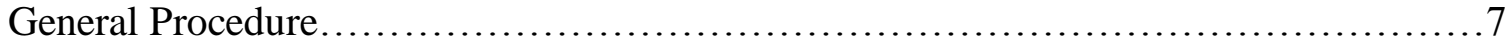

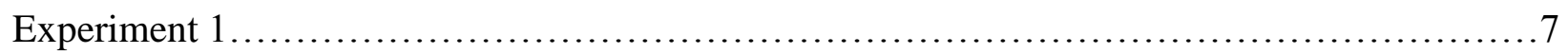

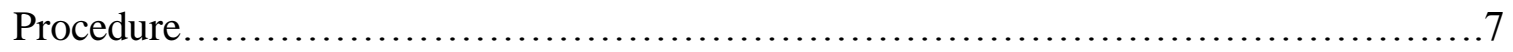

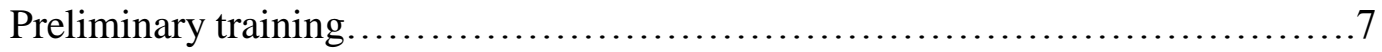

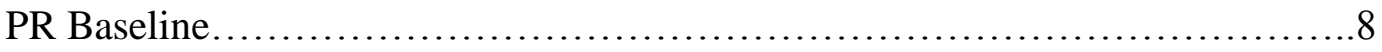

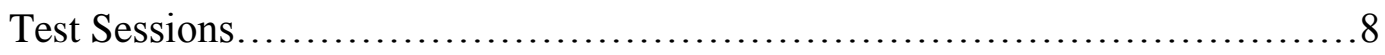

Reinstatement Sessions............................................ 8

PR Phase.................................................... 8

Reinstatement Phase......................................... 8

Control Sessions...................................................

PR Phase................................................... 9

Control Phase..................................................... 9

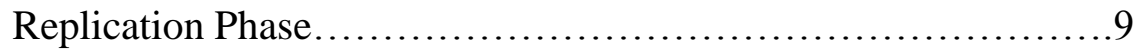

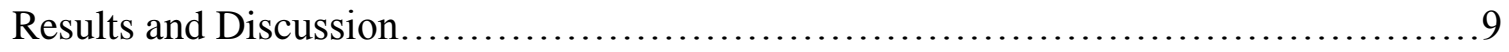

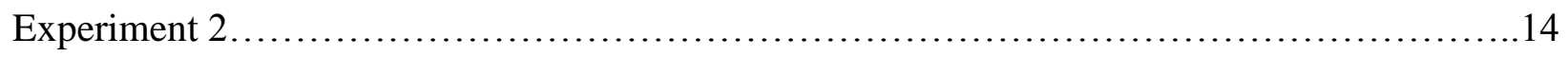

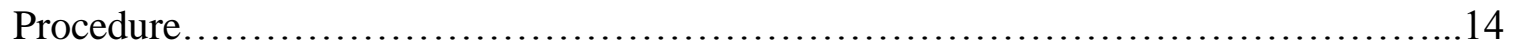

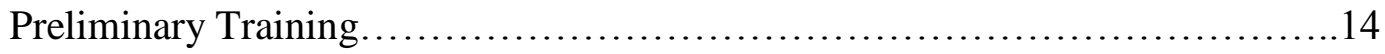

Context A...............................................................

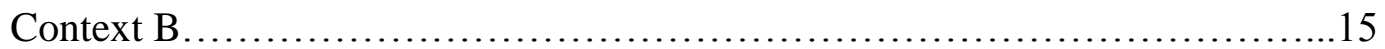

Test Sessions............................................................ 
Renewal Sessions.................................................

PR Phase....................................................15

Renewal Phase.................................................15

Control Sessions................................................ 15

PR Phase........................................................15

Control Phase .............................................15

Sequence of Conditions........................................... 15

Results and Discussion..............................................................

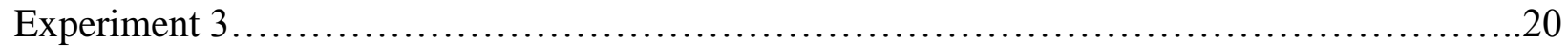

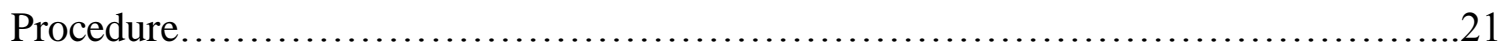

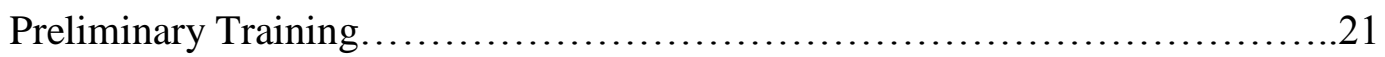

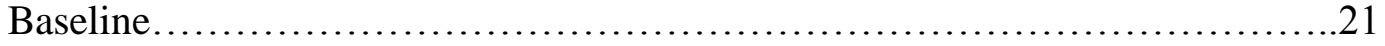

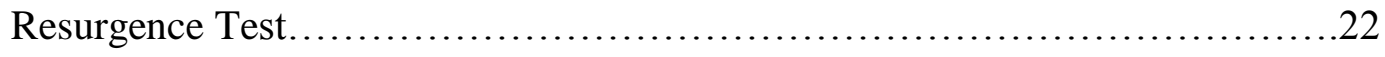

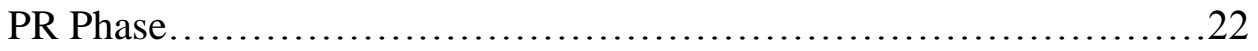

Alternative Reinforcement Phase.......................................22

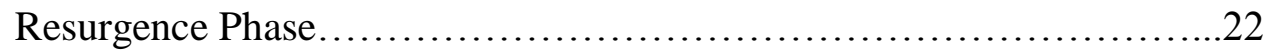

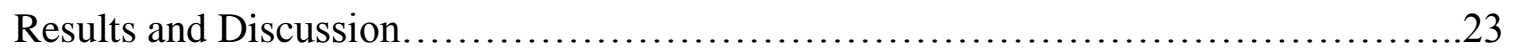

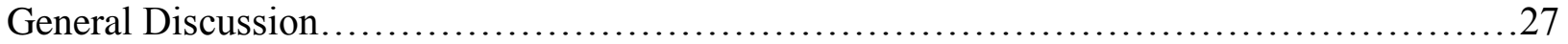

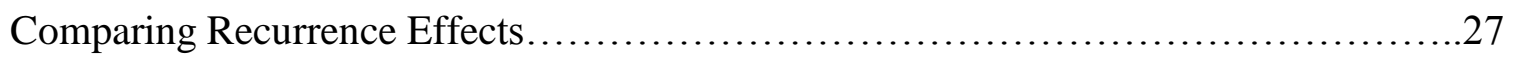

Reinstatement and Resurgence as Renewal.......................................28

Spontaneous Recurrence of Responding ........................................... 31

Translational Implications..................................................... 34

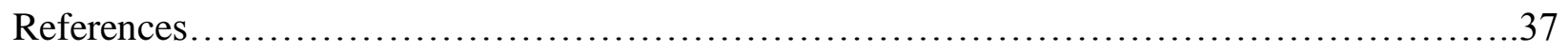

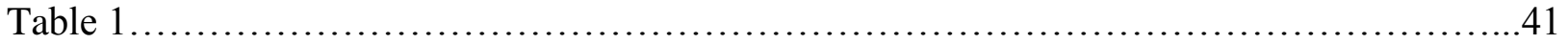

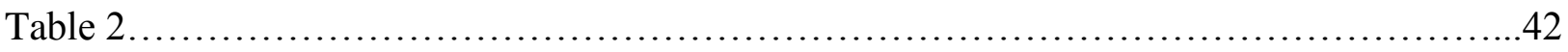

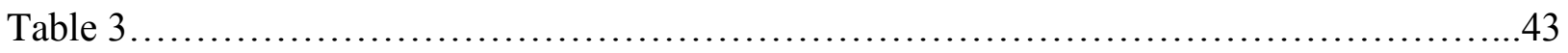

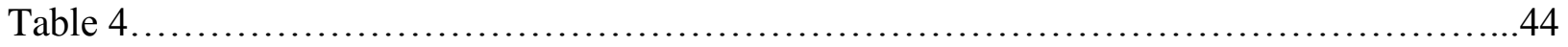

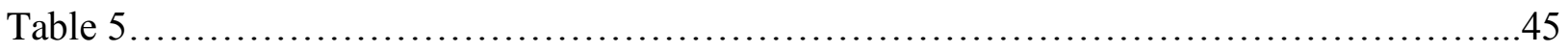




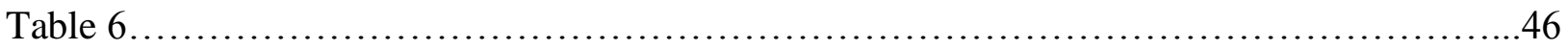

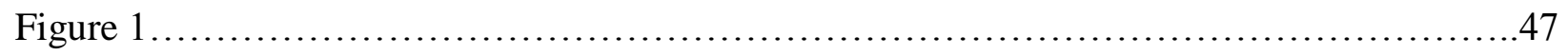

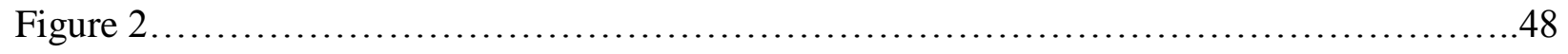

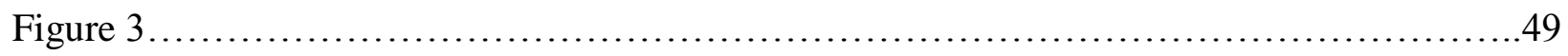

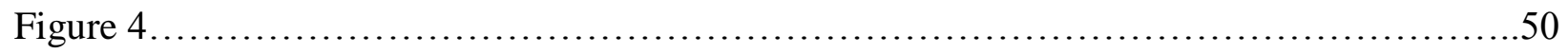

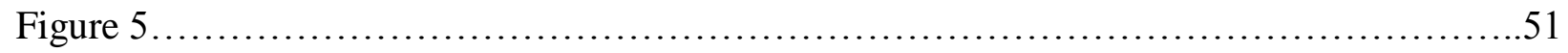

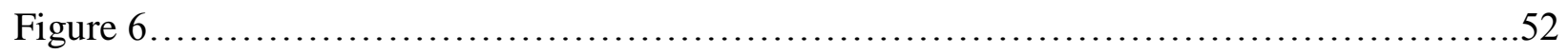

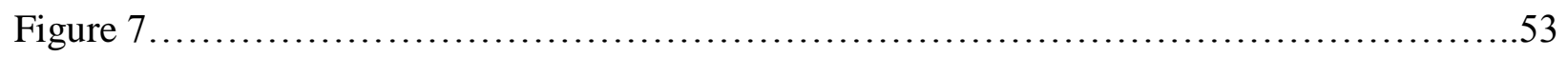


Testing for Recurrence of Ratio-Strained Behavior with

Reinstatement, Resurgence, and Renewal

If more and more responding is required to obtain a reinforcer, behavior eventually becomes "strained." Such strain is characterized by long pauses and erratic patterns of responding. If the response requirement continues to escalate, behavior reaches a breaking point and ultimately ceases altogether for an extended period of time. This phenomenon was described by Ferster and Skinner (1957), particularly in the context of ratio schedules of reinforcement. Strain as a result of increasing demands on behavior is a common experience for many organisms. Bees that have depleted nectar in the closest flower patches may have to fly farther and farther from the hive. A runner may have to increase her mileage by greater and greater amounts to shave a few seconds off her race time. A faculty member may be expected to produce increasing numbers of publications to earn a "satisfactory" rating from the faculty evaluation committee.

One method for systematically studying the breakdown of behavior under increasing response requirements is the progressive-ratio (PR) schedule. As in a fixed-ratio (FR) schedule, in a PR schedule the organism is required to emit a number of responses (the ratio) for reinforcement. The number of required responses, however, increases systematically, usually following each reinforcer. For example, a rat may emit a single lever press that results in a pellet delivery, then emit two lever presses to result in a second pellet delivery, then three responses, and so on. This process continues until responding ceases for a prescribed period of time (the break-point criterion; Hodos, 1961, 1965; Hodos \& Kalman, 1963), at which point, the session is terminated. The primary dependent variable in PR schedule investigations is the "break point," 
or the response requirement of the last completed ratio (Stewart, 1975; Stafford \& Branch, 1998).

Effects of several procedural variations of PR schedules have been described in the literature. PR response requirements can increase arithmetically (e.g., 1, 2, 3, 4) or geometrically (1, 2, 4, 8, 16). Killen, Posadas-Sanchez, Johansen, and Thrailkill (2009) compared arithmetic and geometric PR schedules and found greater persistence of responding at high ratios with geometric progressions relative to arithmetic progressions. Different break-point criteria can also be employed (e.g., 5 min without a response, 10 min without a response). Stafford and Branch (1998) found slightly higher break points with a 15-min break-point criterion relative to a 5-min break-point criterion. Another procedural variation involves changing the step size of the PR schedule (e.g., a step size of 1 would produce ratios 1, 2, 3, etc.; a step size of 10 would produce ratios 10, 20, 30, etc.). Stafford and Branch (1998) investigated step sizes ranging from 1 to 320, and did not find systematic differences in break point as a function of step size. Killeen et al. (2009) investigated step sizes of 2, 3, and 5 and also did not find systematic differences as a function of step size. Thus, it appears that under a given progression with a constant break-point criterion, the break point is relatively immovable.

If strained behavior will be observed at approximately the same ratio regardless of the size of steps taken to get to that ratio, a question is whether anything can be done to recover responding after ratio strain has occurred. Elimination of responding engendered by progressiveschedule requirements and response elimination by extinction (i.e., removal of reinforcement for the response) may be conceptualized as functionally similar processes in that they produce similar behavioral effects (i.e., the elimination or substantial reduction of responding). In effect, 
a break-point criterion is a within-session extinction criterion. Perhaps then the question should be restated as: Can anything be done to recover responding that has been eliminated?

The answer, from decades of research on extinction, is "yes." The conditions under which extinguished behavior "comes back," or recurs have been investigated extensively. These lines of research have produced a number of procedures that reliably result in the recurrence of previously reinforced (but, more recently, eliminated) behavior (see Bouton, 2004, for a review). Such experimental arrangements will be collectively referred to here as "recurrence procedures."

Three recurrence procedures have received particular attention in the behavior-analytic literature: reinstatement, renewal, and resurgence. Reinstatement is the recurrence of previously reinforced (and currently extinguished) behavior when the previously established reinforcer is delivered response independently. In reinstatement procedures, responding is reinforced in the acquisition phase and then extinguished. After responding ceases, the response-independent presentation of reinforcement in the test phase results in the (transient) return of responding (e.g., Franks \& Lattal, 1976; Reid, 1958; Spradlin, Girardeau, \& Hom, 1966; Podlesnik \& Shahan, 2009).

Renewal is the recurrence of previously reinforced behavior when a context change occurs following extinction of the response. This context change may take several forms, but in the most widely studied renewal preparation (ABA Renewal) acquisition of the response occurs in Context A, followed by extinction in Context B. When the original context is re-presented, the extinguished response recurs (Nakajima, Tanaka, Urushihara, and Imada, 2000; Podlesnik \& Shahan, 2009; Gunther et al. 1998, Bouton, Todd, Vurbic, \& Winterbauer, 2011). Renewal studies typically differentiate between contexts by using changes in several background or "contextual" stimuli, which have included different experimental chambers in different 
laboratory rooms, odor, chamber flooring, and striped vs. solid walls (e.g., Bouton et al., 2011). Podlesnik and Shahan (2009) differentiated between contexts with a single stimulus modality (flashing vs. steady houselight) and still observed ABA renewal.

Resurgence is the recurrence of a previously reinforced response when a more recently reinforced response is extinguished (Carey, 1951; Epstein 1983, 1985; Bouton, 2004; Lattal \& St. Peter Pipkin, 2009). Resurgence procedures typically involve three stages. In the first stage, a response is reinforced. In the second stage, an alternative response is reinforced and the original response is extinguished. In the third phase, extinction is in effect for both responses. The return of the original response during the third phase constitutes resurgence. Resurgence has been demonstrated across a wide range of response/reinforcer combinations, in both basic and applied settings (see Lattal \& St. Peter Pipkin for a review).

Although all of the previously described preparations produced reliable recurrence when responding was eliminated by extinction, it is unknown whether they would produce recovery of strained responding under a PR schedule. If response elimination due to ratio strain is functionally equivalent to extinction, then responding should recur following responseindependent reinforcer delivery, reintroduction of the original stimulus context, or extinction of a more recently reinforced behavior (reinstatement, renewal, and resurgence, respectively). This expectation invites experimental analysis. Demonstrating recurrence of responding under any of these recurrence preparations would have implications for understanding behavior under demanding schedule requirements. Response recurrence produced by any procedure would show that strained behavior (like extinguished behavior) is not irreversibly "broken," but rather only temporarily eliminated. Furthermore, such findings would show that responding at the breaking point can be rejuvenated through procedurally straightforward experimental manipulations. 
The previously discussed recurrence effects are transient, usually lasting for a single or small number of test sessions. This is expected, because extinction is in effect throughout the test phase (i.e., no reinforcement is provided for responding generated by the recurrence procedure, so behavior is eventually re-eliminated). In the context of strained ratio responding, nonreinforcement of recurrent responding is not necessarily the case. Under a PR schedule, recurrence effects may be sufficiently robust for responding to contact reinforcement again, which potentially could increase the break point. Given the lack of experimental manipulations to increase break points, recurrence procedures could serve as a powerful tool to push the (thus far, generally immovable) limits of behavior under progressive contingencies.

Even if procedures for inducing response recurrence are not robust enough to substantially affect the break point, a transient but reliable effect also has interesting implications. Although recurrence phenomena are tested in extinction, they often are discussed in terms of the potential to regenerate behavior under conditions of reinforcement (e.g., Bouton et al., 2011). Similarly, the power of applying recurrence procedures to strained behavior may lie in the potential to "jump start" responding that potentially could be reinforced under less demanding schedule requirements. Even a small run of responding engendered by a recurrence procedure may be interesting in terms of power to quickly produce behavior, even if the behavior is not reinforced during testing.

If ratio strain produces "local extinction" of the response, then recurrence procedures applied to strained behavior should produce response recurrence. It currently is unclear which recurrence procedures, if any, might regenerate strained ratio responding. Investigating response recurrence in the context of ratio strain is an important contribution to understanding the dynamics of response elimination in its many forms, as well as the limits of ratio schedules in 
controlling behavior. Thus, the purpose of the proposed experiments is to test reinstatement, renewal, and resurgence procedures in the context of progressive-ratio schedules to determine if these procedures can be used as tools to recover ratio-strained behavior.

\section{General Method}

\section{Subjects}

Experimentally naïve White Carneau pigeons served as subjects for each of the proposed experiments. Three pigeons were used in Experiment 1 and Experiment 3. Four pigeons were used in Experiment 2. Each pigeon was housed individually in a home cage with continuous access to water. Each was maintained at 80 percent of their ad libitum body weight by supplemental feedings with Purina pigeon chow that took place at least 30 min after experimental sessions, as required. The vivarium where the pigeons were housed at times other than during experimental sessions was illuminated according to a $12 \mathrm{hr}: 12 \mathrm{hr}$ light: dark cycle.

\section{Apparatus}

Three operant-conditioning chambers, $32 \mathrm{~cm}$ long by $30 \mathrm{~cm}$ high by $30 \mathrm{~cm}$ wide, each located in a sound-attenuating enclosure, were used. An aluminum work panel, comprising one wall of each chamber, contained three $2.54 \mathrm{~cm}$ diameter response keys. Keys were centered on the midline of the panel, with the lower edge $11 \mathrm{~cm}$ from the floor. Each key was operated by a force of approximately $0.15 \mathrm{~N}$. Keys were transiluminated white or a color. Operative keys and their colors varied by experiment, as described below. Reinforcement was 3-s access to Purina pigeon chow made available from a hopper located behind a $4.5-\mathrm{cm}$ square feeder aperture located on the midline of the work panel with its lower edge $9 \mathrm{~cm}$ from the chamber floor. When the hopper was raised to be accessible through the aperture, the aperture was illuminated by a white light. General chamber illumination was provided by a houselight located in the bottom 
right corner of the work panel. The houselight was on whenever the keylight was on. White noise and a ventilation fan masked extraneous noise. A personal computer, located in adjacent room, operated MedPC7 software, which in turn controlled the experiment.

\section{General Procedure}

Daily sessions occurred at approximately the same time each day. Each session commenced following a 3-min chamber blackout, during which the houselight and all key lights were off. The function of this blackout was to minimize effects of handling on subsequent session performance.

\section{Experiment 1}

The first recurrence procedure discussed in the introduction was reinstatement, which involves the response-independent presentation of the previously established reinforcer. Thus, the first recurrence procedure tested in the context of ratio-strained behavior was reinstatement by response-independent food deliveries.

\section{Procedure}

Preliminary training. Before this experiment, key pecking to the center key was shaped. Only the center key was transilluminated during the shaping sessions. After reliable key pecking was observed, two pigeons $(822,1189)$ immediately began the PR baseline condition. One pigeon (2215) exhibited considerably lower break points than 822 and 1189 when placed on a PR 10 schedule, so the step size of the schedule was decreased from 10 to 5 for this pigeon, to more adequately equate obtained reinforcers across pigeons. The PR baseline began with the first session of the PR 5 schedule for 2215. An additional pigeon (1495) completed preliminary training but schedule control was not observed when this pigeon was placed on the PR schedule, and data for this pigeon will not be reported. 
PR Baseline. Pecks to the center key were reinforced according to an arithmetic PR schedule. The step size of the PR was 10 for pigeons 822 and 1189 (10 responses were required to deliver the first reinforcer, 20 responses for the second reinforcer, 30 responses for the third, etc.), and the step size was 5 for 2215. A 5-min break-point criterion was in effect (i.e., sessions terminated following 5 min without a response). The right key served as a control key that was lighted whenever the center key was on, but pecks to the right key never resulted in reinforcer presentation. The PR baseline was in effect for at least 10 sessions and until no upward or downward trends in break points were observed in the last six sessions.

Test Sessions. Two types of test sessions were conducted: reinstatement sessions with response-independent food delivery after the break point and control sessions in which no food was delivered after the break point. Table 1 shows the sequence of conditions and number of sessions for each pigeon. Each PR baseline was in effect for at least 10 sessions and until stable break points were observed between each test session.

Reinstatement Sessions. Reinstatement sessions consisted of two within-session phases: the PR Phase and the Reinstatement Phase.

PR Phase. The PR phase was identical to a PR baseline session (reinforcers were delivered according to the PR schedule) except that instead of the session terminating when the 5-min break point criterion was met, the Reinstatement Phase began.

Reinstatement Phase. During this phase, extinction was in effect (i.e., additional keypecks did not result in reinforcer presentation) and food was delivered response independently. In the first reinstatement session, the schedule of response-independent food delivery was yoked to the reinforcement deliveries that occurred in the previous PR baseline session (i.e. yoked time, YT, schedule). The session terminated immediately following the last 
YT food delivery. In the second reinstatement session, food deliveries occurred on a fixed-time (FT) $30 \mathrm{~s}$ schedule. The number of FT food deliveries was yoked to the number of YT food deliveries in the preceding baseline session.

Control Sessions. Control sessions consisted of 3 phases: the PR Phase, Control Phase, and Reinstatement Replication Phase.

PR Phase. This phase was identical to the PR phase of the reinstatement sessionsexcept that when the 5 minute break-point criterion was met, instead of the session terminating, the Control Phase began.

Control Phase. During this phase, the session was extended. Extinction was in effect and no response-independent food deliveries occurred. The duration of this phase was yoked to the duration of the Reinstatement Phase of the preceding reinstatement session.

Replication Phase. During this phase, response-independent food deliveries were provided as in the reinstatement sessions. The number of food deliveries was yoked to the food deliveries provided in the preceding reinstatement session.

\section{Results and Discussion}

Table 2 shows the mean and range of break points for the last six sessions of each PR baseline, as well as the break points obtained during the PR Phase of reinstatement and control sessions. Break points were somewhat variable across successive baseline conditions, though break points observed during test sessions were often within the range of the preceding six baseline sessions. No responding occurred on the control key except during some early sessions of preliminary training. Figure 1 shows overall response rates during Reinstatement, Control, and Replication Phases of test sessions. Pigeons 822 and 2215 exhibited nearly identical patterns of responding across phases. Reinstatement of responding occurred with both the yoked-time 
and fixed-time reinstatement procedures. In the absence of food delivery (i.e., during Control Phases) these two pigeons responded at a low rate (19.3 and 24.8 responses per minute respectively for the first Control Phase), or not at all (the second Control Phase). Pigeon 1189 also responded at a higher rate in the first YT reinstatement Phase relative to the control condition, but did not respond at all during the YT Replication Phase. This pigeon responded at a low rate during the initial FT Reinstatement Phase, but responded at a higher rate relative to the control during the FT Replication Phase.

Figure 2 shows within-session response rates during reinstatement sessions and control sessions for each pigeon. During the PR Phase of the session, response rates generally were stable prior to the last (incomplete) ratio. Response rates for the last ratio are always near-zero because the PR schedule was terminated after a 5 min period of no responding, thus, the denominator of the response rate calculation for the last ratio is at least $5 \mathrm{~min}$. Recurrence of responding during the YT Reinstatement Phase occurred after several (i.e., 3-5) food deliveries. Recurrence of responding during the FT ReinstatementPhase occurred following a single food delivery. The greater number of food deliveries required to observe recurrence during YT tests is likely due to the yoking procedure. The first several food deliveries are yoked to interreinforcement intervals for short ratio requirements, and therefore occur rapidly, providing only short periods in which the pigeon can emit a response.

Some responding occurred during the Control Phase of the first control session for all pigeons. This responding always took longer to emerge and occurred at a lower rate relative to responding observed during reinstatement tests. The exception is the FT Reinstatement Phase and Control Phase for Pigeon 1189. Although this pigeon resumed keypecking more rapidly in 
the first FT Reinstatement Phase relative to the Control Phase, more responding was observed in the Control Phase.

In summary, two pigeons showed consistent evidence for a strong reinstatement effect after their responding reached the break-point criterion of the PR schedule. Time-based food deliveries, whether scheduled to mimic response-dependent reinforcement (via a YT schedule) or scheduled to occur at regular intervals (via an FT schedule), resulted in recurrence of responding. Rates of recurrent responding, assessed at the each food delivery, resembled rates of responding observed for response-dependent food deliveries on the progressive ratio schedule. Furthermore, this recurrence occurred rapidly even when the food deliveries occurred following an extended period in which no food deliveries occurred (as in the control session).

The pattern of results was less systematic for Pigeon 1189. It exhibited the greatest range of break points of the three pigeons in the study (see Table 2), and responded more in extinction (i.e., Control Phases) than did the other two pigeons (see Figure 2). This pigeon did show evidence of reinstatement during the YT Reinstatement Phase and the FT Replication Phase condition, but did not show a clear effect in other Reinstatement Phases. Unlike the other pigeons, in which a pause of 5 min predicted a much longer period of near-zero responding, 1189 engaged in high rates of post-break point responding regardless of the condition.

The design of the session extension as a control procedure presumes that responding will not spontaneously recur after the break-point criterion is met. In the same way that a more stringent extinction criterion increases confidence in the prediction that responding will not spontaneously recur in a traditional extinction procedure, use of a more stringent break point criterion may increase confidence that post-break point responding will not recur. Spontaneous recurrence of behavior during the Control Phase may also be a function of the amount of training 
on the PR schedule. For all pigeons, there was some recurrence of behavior the first time these pigeons were exposed to a session that did not terminate after $5 \mathrm{~min}$, but this recurrence was not observed for two of the three birds when the session was extended a second time. Thus, extensive training on a PR schedule with a 5-min break-point criterion may have attenuated this spontaneous recurrence for two of the three birds. It is unclear, however, why this was not the case with 1189. Further investigation may clarify the effects of 1) more stringent break-point criteria and 2) amount of PR training on the amount of responding observed when the session is extended past the break point, which may help account for the individual subject differences observed in the present study.

Taken together, these data provide evidence that reinstatement procedures can result in reinstatement of ratio-strained behavior. The present study extends the well-established finding that delivering a reinforcer independently of responding is sufficient to reinstate extinguished responding (e.g., Franks \& Lattal, 1976, Reid, 1958; Spradlin, Girardeau, \& Hom, 1966; Podlesnik \& Shahan, 2009) to conditions in which responding was eliminated under demanding schedule requirements. This extension is important, because it is likely that much behavior in naturalistic environments is eliminated because reinforcers often become increasingly difficult to obtain over time, rather than being eliminated altogether (i.e., formal extinction).

When reinstatement was observed, the number of responses emitted was far greater than the break point ratio requirement. Not all of this responding can be attributed to the reinstatement effect in isolation, because adventitious temporal contiguity of responses and food deliveries (“adventitious reinforcement," Skinner, 1948) likely occurred during the reinstatement condition. Therefore, it is reasonable to assume that the effect observed during the reinstatement condition was partially due to adventitious reinforcement by the YT or FT schedule that 
maintained responding. This assumption is supported by the maintenance of responding throughout the reinstatement condition. Adventitious reinforcement cannot easily account for the initial response recurrence, however, because response-independent food deliveries did not occur until the pigeon had stopped responding for $5 \mathrm{~min}$. Thus, the probability of a response being adventitiously reinforced by the initial response-independent food presentation was minimized, consistent with prior reinstatement studies (see Franks \& Lattal, 1976 for further discussion of adventitious reinforcement related to reinstatement).

Because it is impossible to parse apart the relative contributions of reinstatement and adventitious reinforcement to the observed response recurrence, one cannot determine from these data whether the reinstatement alone would have resulted in enough responses for the pigeon to obtain additional reinforcers, and therefore increase the break point, had the progressive ratio schedule remained in effect. A future experiment might investigate this question by delivering response-independent food until a response occurs, then discontinuing response-independent food and presenting the progressive ratio schedule again. Reinstatement was observed with as little as a single food delivery, but it is unclear if different numbers of response-independent food deliveries would result in different levels of persistence on a PR schedule reintroduced after reinstatement.

Even if reinstatement does not increase the break point, the present results indicate that the effect can produce a quick burst of responding that could potentially contact reinforcement under less demanding schedule requirements. Such a procedure could be a useful tool in applied settings. One of the most popular approaches for managing ratio strain in application is to back up to a richer schedule of reinforcement (e.g., Hagopian, Fisher, \& Legacy, 1994). This approach is limited, however, because enriching the schedule is not a functional treatment 
change unless the individual engages in behavior that can contact the enriched schedule. In cases in which backing up to a richer schedule is ineffective, a practitioner might use a reinstatement procedure to quickly jump-start responding, then reinforce the reinstated response. Thus, the present results indicate the promise of a reinstatement approach that could be easily integrated to enhance current treatment techniques.

\section{Experiment 2}

A second procedure reliably shown to produce recurrence of extinguished behavior is ABA renewal. In this experiment, an ABA renewal procedure was tested in the context of ratiostrained responding.

\section{Procedure}

Preliminary training. Before this experiment, key pecking to the center key was shaped. The color of the center key was the same color used in Context A sessions described below (see Table 3). After reliable key pecking was observed, one session of schedule leaning was conducted in which the number of key peck responses to result in food presentation was increased within session to 20. After this leaning session, a VR schedule was in effect. The VR schedule was constructed from Fleshler-Hoffman (1962) progressions, rounded to the nearest integers, with total of 12 ratio values. The mean ratio of the VR schedule was increased across sessions to a terminal value of VR 20, at which point the experiment proper began.

Context A. One response key was transilluminated with a color (the "main key," see Table 3), and one response key (the "control” key) was white. Reinforcement was made available for pecks to the colored key according to a VR 20 schedule. Pecks to the white key did not result in reinforcer presentation. Sessions terminated following 60 reinforcer deliveries. The Context A condition was effect for 10 sessions. 
Context B. The main key was a different color during this phase of the study (see Table 3), the control key remained white. Reinforcement was arranged for pecks to the main key by a PR 10 schedule. A 5-min break-point criterion was in effect (i.e., sessions were terminated following 5 min without a response). The Context B condition was in effect for 10 or five sessions (see Table 3 and "Sequence of Conditions," below).

Test Sessions. Two types of test sessions were conducted: tests for renewal in Context A and control sessions in which the context did not change.

Renewal Sessions. Renewal sessions consisted of two phases: the PR Phase and the Renewal Phase.

PR Phase. This phase was identical to a Context B session except that when the 5-min break-point criterion was met, instead of the session terminating, the Renewal Phase began.

Renewal Phase. At the start of this phase, the color of the main key was changed to the same color presented during the Context A sessions (see Table 3), with extinction in effect (i.e., reinforcement was not provided for key pecking). The session terminated when the 5-min breakpoint criterion was met a second time (i.e., 5 min without a response).

Control Sessions. Control sessions consisted of a PR Phase and a Control Phase.

PR Phase. The PR Phase was identical to the PR Phase of renewal sessions except that, after the 5 min break-point criterion was met, the Control Phase began.

Control Phase. During this phase, the session was extended. No key color changes occurred and extinction was in effect. The duration of this phase was yoked to the duration of the Renewal Phase in the previous renewal session.

Sequence of Conditions. Table 3 shows the sequence of the previously described conditions. After preliminary training, all pigeons were exposed to Context A, then Context B, 
then a renewal session. Following this initial renewal session, two of the four pigeons repeated the $\mathrm{AB}$ sequence (10 sessions in Context $\mathrm{A}, 10$ sessions in Context $\mathrm{B}$ ), before completing a control session. The other 2 pigeons were not re-exposed to Context A after the first renewal session, but rather proceeded directly to Context B followed by a control session. The purpose of this manipulation was to assess what effects (if any) returning to the original conditioning context would have on responding observed during the control session.

After the control session, the renewal procedure was replicated. During the replication, the order of conditions was identical for all pigeons (Context A, Context B, renewal session, Context B, control session) but the number of Context B sessions conducted in the condition immediately preceding the control session was decreased from 10 to 5 . The purpose of this procedural change was to assess differences in responding in the control session as a function of a decreased number of intervening sessions between Context A and the control session.

\section{Results and Discussion}

Table 4 shows the response rates for the last five sessions of Context A, break points for the last five sessions of Context B, and the break points obtained during the PR phase of renewal and control sessions. Break points were somewhat variable across successive baseline conditions, though break points observed during renewal and control sessions were often within the range of the preceding five baseline sessions. No responding occurred on the control key except during some early sessions of preliminary training.

Figure 3 shows the number of responses during Renewal and Control Phases. Renewal of responding occurred in all Renewal Phases, and little or no responding occurred when the session was simply extended (i.e., the Control Phase). Returning to Context A following the renewal test did not systematically affect the amount of responding observed in the Control 
Phase. More renewal was observed in the second Renewal Phase for three out of four pigeons. This can perhaps be attributed to the greater total number of sessions of exposure to Context A that preceded the second renewal session. Greater responding also was observed in the second Control Phase relative to the first Control Phase for two of the three pigeons $(17428,19841)$, which can perhaps be attributed to the fewer number of Context B sessions that intervened between Context A and the second control session. However, this responding was much less than that observed during Renewal Phases.

Figure 4 shows the temporal distribution of responding, through cumulative records, during the first renewal and first control session for each pigeon. The cumulative record stops at the last response that occurred during the session. During the PR Phase, pigeons responded at a generally consistent rate, albeit with increasingly long postreinforceement pauses as the ratios incremented, until the last (incomplete) ratio, consistent with the progressive ratio performance observed in Experiment 1. Recurrence of responding during the Renewal Phase occurred rapidly following the key color change. When responding occurred during the Control Phase (Pigeon 17428), this responding typically occurred in the form of a short burst of responses.

During Renewal Phases, the number of responses emitted often was greater than the break point ratio requirement, suggesting that the renewal effect observed here was in many cases powerful enough to allow the pigeon to obtain additional reinforcers, had the PR schedule remained in effect. The recurrence of responding demonstrated in this experiment was obtained without additional food presentations, so the persistence of responding can be attributed to the stimulus change (and not to adventitious reinforcement, as was possible in Experiment 1). It is impossible to tell, however, if further persistence of responding on the PR schedule would occur if the schedule were reintroduced, and if this persistence would result in a reliably higher break 
point. A study integrating a renewal effect with re-introduction of the PR schedule could be one extension of the present experiment.

A potential limitation of the present study is that renewal sessions always were conducted prior to control sessions. Because Control Phases yoked to Renewal Phase durations were preceded by more PR training than renewal sessions, it is not possible to predict whether some responding that was observed during the first renewal session would have occurred without the key color change (i.e., if the control session had been conducted first), due to the short number of PR training sessions (10) that preceded this session. Because the magnitude of the renewal effect was undetermined prior to this investigation, this procedure yoked the duration of the Control Phase to the duration of the Renewal Phase, which was in turn determined by how long renewed responding persisted. This yoking procedure necessitated that renewal sessions were conducted before control sessions. It is unlikely, however, that spontaneous post-break point responding can account for much of the recurrence observed here, given that the amount of responding observed during the first Renewal Phase was far greater than responding that was observed during any Control Phases in Experiment 1. Furthermore, the fact that recurrence of responding during Renewal Phases occurred rapidly following the key color change provides evidence that this responding was under the control of the key-color manipulation.

In summary, these data provide evidence that an ABA renewal procedure can consistently result in renewal of behavior eliminated by demanding schedule requirements. This experiment extends the well-established finding that changing the context to a context previously paired with high-rate reinforcement is sufficient to reinstate extinguished responding (Nakajima et al., 2000; Podlesnik \& Shahan, 2009; Bouton et al., 2011) to conditions in which responding was eliminated as the response requirements of a PR schedule incremented. The renewal effects 
observed here were immediate and resulted in high-rate behavior, suggesting that the context change is a powerful manipulation for causing recurrence.

Aside from the use of a PR schedule instead of extinction for response elimination, some procedural differences of the present study with respect to other renewal studies may warrant consideration. Seminal experiments (Nakajima et al., 2000; Bouton et al., 2011) investigating renewal of operant behavior used contexts that differ along several stimulus modalities (including different experimental chambers in different laboratory rooms, odor, chamber flooring, and striped vs. solid walls) in contrast to the present study in which only a key color change differentiated contexts. Podlesnik and Shahan (2009) also differentiated between contexts with a single stimulus modality, but a modality different from the one employed in this procedure (flashing vs. steady houselight). Thus, the results of the present experiment concur with those of Podlesnik and Shahan, further demonstrating that that change in a single stimulus modality is sufficient to observe renewal when the context change involves a return to a context previously paired with reinforcement.

The present experiment used an ABA renewal design, in which the context changed back to a context associated with a dense schedule of reinforcement. It is unclear from the present results, however, how this history of responding in Context A affected the subsequent renewal effect. In some variations of renewal procedures, the context change does not change back to a context previously associated with reinforcement, but rather to a novel context (i.e., $\mathrm{ABC}$ renewal procedure). Because renewal was observed regardless of whether the context was novel or previously associated with reinforcement, Bouton and colleagues (2011) argue that the renewal effect is driven by the context-specificity of operant extinction, rather than the history of the changed-to context. If ABA renewal of ratio-strained behavior were demonstrated, then a 
similar explanation could be applied to ratio-strain, namely, that behavior eliminated by demanding schedule requirements is particularly context-specific. This hypothesis requires further investigation, considering the few number of studies demonstrating renewal of operant behavior without returning to a reinforcement context (Bouton et al., 2011).

Understanding the necessary and sufficient context changes to observe renewal, particularly renewal of ratio-strained behavior, may have implications for how the effect may be used in treatment contexts. If the context shift simply requires a change from the current context in which ratio strain has occurred, then a practitioner might need only to switch session rooms or therapists to cause renewal of the target response. Such an effect would only be expected if 1) $\mathrm{ABC}$ renewal of operant behavior is reliable and 2) the present results can be replicated with $\mathrm{ABC}$ renewal. Regardless of whether other renewal procedures are effective in regenerating ratio-strained behavior, the present study indicates that an ABA renewal procedure could be an effective technique. The implementation of $\mathrm{ABA}$ renewal in treatment contexts may require some foresight on the part of the practitioner, because a history of reinforcement in a context different from the context of reinforcement thinning must be established. For example, a therapist might work with a student in a dense reinforcement treatment context (Context A) and after acquiring the response, transfer the student to a different therapist (Context B) to conduct reinforcement thinning. If ratio strain is encountered during the thinning process, returning to the original treatment therapist could cause a burst of responding that could contact a more dense reinforcement schedule. Understanding which context changes are salient and feasible to implement in a treatment context could provide a useful extension of the present study to behavioral treatment regimens.

\section{Experiment 3}


Reinstatement and renewal procedures produced recurrence of ratio-strained responding. The final recurrence procedure discussed in the introduction was resurgence. For the third experiment, a resurgence procedure was applied to ratio-strained behavior.

\section{Procedure}

Preliminary training. Before the experiment proper, shaping of responding on the right (red) key was conducted. After reliable key pecking was observed, one session of schedule leaning was conducted in which the number of key peck responses required for reinforcement was increased within session to a ratio requirement of 20 .

Table 5 shows the sequence of conditions for the experiment proper (i.e., all sessions following the leaning session). After the leaning session, a fixed-ratio (FR) 10-s schedule was in effect. The purpose of the FR 10 sessions was to establish a history of responding for reinforcement on the right key, such that illumination of the right key would occasion responding during the resurgence test (described below). Each session of FR 10 terminated after 60 reinforcer deliveries. Following 10 sessions of the FR 10 schedule, the baseline schedule was introduced. Two pigeons $(17189,14049)$ did not peck the key when the baseline schedule was introduced, so one session of shaping was conducted in the presence of the green key before the baseline condition began.

Baseline. The center key was transilluminated green. Pecks to this key were reinforced according to an arithmetic PR 10 schedule. A 5-min break-point criterion was in effect (i.e., sessions were terminated following 5 min without a response). The PR baseline was in effect for at least 10 sessions and until no upward or downward trends in break points were observed over the last six sessions. 
Resurgence Test. Each resurgence test was conducted within a single three phase test session.

PR Phase. During the PR Phase, pecks to the center green key were reinforced according to the PR 10 schedule. When the 5-min break-point criterion was met, instead of the session terminating, the Alternative Reinforcement Phase began.

Alternative Reinforcement Phase. This phase began with turning on the keylights behind both side keys such that now all three keys in the chamber were transilluminated. Pecks to the center key no longer produced reinforcement. The left key was white and served as a control key (i.e., pecks to that key never produced reinforcement). The first three pecks to the right (red) key produced reinforcement (i.e., FR 1 schedule with 3 reinforcer deliveries), subsequent pecks produced reinforcement according to an FR 10 schedule. After all right-key reinforcers were delivered, The Resurgence Phase began.

Resurgence Phase. In the Resurgence Phase, all keys remained transilluminated but pecks to any of the keys did not produce reinforcement. The session was terminated after some period of time passed without a response. A singe pilot resurgence test was conducted with Pigeon 17189 in which 20 total right-key reinforcers were delivered and the session was terminated after 5 min without a response. During the Resurgence Phase of this pilot session, in which extinction was in effect for all responses, responding persisted on the FR key a total of 1183 responses. Little responding was observed on the Resurgence and Control keys (29 and 27 responses, respectively). Because resurgence was not observed during this pilot session, the test procedure was modified such that 40 total reinforcers were delivered during the Alternative Reinforcement Phase before extinction of responding on that key was effected, and the session 
terminated following $10 \mathrm{~min}$ without a response. Three sessions of this resurgence test procedure were conducted for each subject on the successive days.

\section{Results and Discussion}

Table 6 shows the response rates for the last five sessions of Pretraining, break points for the last five sessions of Baseline, and the break points obtained during the PR phase of test sessions. Break points were somewhat variable across pigeons, though break points observed during test sessions were often within the range of the preceding five baseline sessions.

Figure 5 shows the temporal distribution of responding, through cumulative records, on the PR key across the PR and Alternative Reinforcement Phases of the first (Piegons 11718 and 17189) or second (Pigeon 14049) resurgence test session. Typical response patterns were obtained during the PR Phase, that is, responding was at a consistent rate with increasing postreinforcement pauses until the break point ratio requirement. The pigeons responded little, if at all, on the PR key during the Alternative Reinforcement Phase of the session.

Figure 6 shows the number of responses on each response key during the Resurgence Phase of the resurgence test sessions. Resurgence of responding on the PR key was observed in first session of testing for 11718 and 17189 , and in the second session of testing for 14049 . Little responding occurred on the control key, suggesting that the resurgence effect was a function of the history of reinforcement on the PR key, and not simply due to extinction-induced variability. Throughout the Resurgence Phase, the most responding occurred on the FR key. Prolonged responding on the FR key likely can be attributed to the recent and rich history of reinforcement on that key that was programmed in the immediately preceding phase of the session. Resurgence of responding on the PR key occurred on only one of the test sessions for all pigeons. 
Figure 7 shows the within-session response rates on all keys throughout the Resurgence Phase of these sessions. Responses are summed in consecutive 5-min bins. For two of the three pigeons, responding on the FR key declined within the first 20 min of the Resurgence Phase, then persisted at a low, sporadic rate for the duration of the session. Pigeon 14049 responded on the FR key at a high but variable rate for approximately two hours, then declined but persisted at a low rate for the duration of the session. For all pigeons, resurgence of responding on the PR key emerged when responding declined on the FR key. Resurgence was observed in the form of a burst of responding that quickly declined (i.e., within $10 \mathrm{~min}$ ). The amount of responding observed during the Resurgence Phase was greater than the break point ratio requirement for all pigeons, suggesting that the resurgence effect observed here would have been powerful enough to allow the pigeon to obtain additional reinforcers, had the PR schedule remained in effect. As in Experiment 2, determining whether further persistence of responding on the PR key would result in a reliably higher break point could be an extension of the present experiment.

In summary, these data provide evidence that discontinuing reinforcement for an alternative response can produce resurgence of ratio-strained behavior. This study extends the phenomenon of resurgence (see Lattal \& St. Peter Pipkin, 2009, for a review) to conditions in which the first response was eliminated under demanding schedule requirements. Consistent with previous investigations of resurgence (Carey, 1951; Reed \& Morgan, 2006), recurrence of the first response emerged following the decline of the second (alternative) response.

It is unclear why the resurgence effect was not replicated across successive resurgence tests in this experiment, and why the effect emerged in the second test session for one pigeon but the first session for the others. It is possible that a different variation of the resurgence procedure may result in a more powerful resurgence effect that can be replicated across successive tests. If 
resurgence depends on extinction of the alternative response (as is assumed within the resurgence literature, see Lattal \& St. Peter Pipkin, 2009), then decreasing the resistance to extinction of the alternative response may increase resurgence. After failing to observe resurgence in the pilot session with Pigeon 17189, two changes to the resurgence procedure followed. One change (increasing the extinction criterion from $5 \mathrm{~min}$ to $10 \mathrm{~min}$ ) was designed to prolong exposure to extinction, such that the pigeon could pause for more than five minutes on the FR alternative key before resuming responding on the PR key. Although these modifications did yield resurgence for the pigeon that underwent the pilot session (17189), it is impossible to tell if this resurgence would have been observed upon a second exposure to the same pilot procedure, given that Pigeon 14049 did not exhibit resurgence during the first session but did show the effect during the second session. Nonetheless, if the revised procedure was responsible for generating resurgence, then a different alternative reinforcement procedure (e.g., continuous reinforcement) resulting in more rapid extinction may result in greater magnitude, and possibly more reliable, resurgence.

It is possible that the break-point criterion used in this experiment may have affected the reliability of the resurgence effect. The procedure used here differs from much of the resurgence literature in that the first response was eliminated prior to the introduction of reinforcement for the second response. In several studies there has been an inverse relation between degree of extinction of the originally trained response and the degree of resurgence of this response, such that thorough extinction decreases the likelihood of resurgence (Leitenberg, Rawson, \& Bath, 1970; Rawson, Leitenberg, Mulick, \& Lefebvre, 1977; Cleland, Foster, \& Temple, 2000). Epstein (1983; cf. Lieving \& Lattal, 2003) used a resurgence procedure in which the first response was eliminated prior to the introduction of alternative reinforcement, and observed 
resurgence in all subjects. Thus, elimination of the first response prior to the introduction of alternative reinforcement appears to reduce, but not necessarily eliminate resurgence. If these findings can be generalized to ratio strained behavior, then changing the break-point criterion may affect the magnitude of the resurgence effect. Because the break-point criterion is similar to an extinction criterion, a more lax break-point criterion (e.g., 2 min) may increase resurgence, whereas a more stringent break-point criterion (e.g., $10 \mathrm{~min}$ ) may attenuate the effect. Thus, behavior that is less "strained" (that is, less thoroughly eliminated) may be more likely to resurge. Nonetheless, the resurgence effect was still observed even though the present procedure required responding on the PR key to be eliminated for five minutes prior to the introduction of the Alternative Reinforcement Phase.

Understanding the relation between degree of behavioral ratio strain and the subsequent resurgence of ratio-strained responding may have important implications for how the present results may be translated into applied settings. If more strained responding is less likely to resurge, then a practitioner might be wise to implement a resurgence procedure when the behavior begins to show signs of strain. For example, if a student begins to struggle while completing the necessary steps of a problem on a homework assignment, a therapist might encourage the student to work on another problem for a while, then return to the first problem. It also may be worthwhile to note that in applications of resurgence to recover ratio strained responding, problem behavior may serve as the "alternative" response. Take, for example, a teacher that made a concerted effort since the beginning of the year to reinforce students for raising their hands. Over time, the teacher's acknowledgement of hand raising waned, and he began reinforcing students for talking out more frequently. As a result, his students hand raising begins to show sign of ratio strain (they raise their hands repeatedly, but don't get a response, 
and therefore stop raising their hands), as talking out increases. By eliminating reinforcement for talking out, the teacher may observe a resurgence of appropriate behavior with the recurrence of hand raising. Thus, resurgence of ratio-strained behavior may be a useful technique to address deficits in procedural integrity that may occur in the course of behavioral treatment.

\section{General Discussion}

The present experiments extend numerous studies demonstrating the reinstatement, renewal, and resurgence of extinguished behavior to circumstances in which behavior was eliminated by a PR schedule. This finding is consistent with the suggestion that ratio strain produces a kind of "local extinction" of the response, and similar processes affect behavior eliminated by the complete removal of reinforcement and behavior eliminated by difficult-toobtain reinforcement (i.e., demanding schedule requirements). Most importantly, the present experiments suggest that several operations can be used to recover ratio-strained responding. Thus it appears that ratio-strained behavior, like extinguished behavior, is not "unlearning" or erasure of the response. Rather, these experiments suggest that ratio strain produces behavior that is eliminated under very specific circumstances, and such behavior can recur with environmental changes.

\section{Comparing Recurrence Effects}

All three procedures produced recurrence, but differences in the immediacy and reliability of the effects were observed across experiments. Renewal and reinstatement produced recurrence quickly, with responding reemerging almost immediately when the key color changed in the renewal procedure, and after only a few food deliveries in the reinstatement procedure. In both procedures, recurrence was observed within a few minutes of the post-break point manipulation. The resurgence effect was the slowest to emerge, as recurrent responding was 
only observed after the alternative response declined. Renewal resulted in the most reliable recurrence, demonstrated in all subjects in both the original test and the replication.

Reinstatement was also quite reliable, observed in all tests for two of the three pigeons and two out of four tests for the third pigeon. Resurgence was the least reliable effect, occurring in one out of the three test sessions with each pigeon. Some variables that may affect the reliability of the resurgence procedure will be considered in a later section of this manuscript.

\section{Reinstatement and Resurgence as Renewal}

Though reinstatement, resurgence, and renewal have been investigated and discussed independently in prior and the present experiments, Winterbauer and Bouton (2010) have suggested that multiple recurrence phenomena may in fact be variations of a single responserecurrence process. Specifically, they proposed that resurgence may be conceptualized as a type of $\mathrm{ABC}$ renewal, in which reinforcement of the original response and reinforcement of an alternative response serve as Contexts A and B, respectively. When neither response produces reinforcement (extinction) this creates a third set of conditions that may serve as Context C, producing recovery of the originally reinforced response. A similar interpretation could be applied to reinstatement, in which the presentation of food during the baseline phase serves as Context A, absence of food presentations in the extinction phase serves as Context $\mathrm{B}$, and the (response-independent) food presentations in the reinstatement phase serve as Context A. Alternately, reinstatement could be conceptualized as ABC renewal in which response dependent food deliveries and response-independent food deliveries serve as contexts A and C, respectively. 
The ease with which renewal can subsume other recurrence phenomena relies on the fact that the definition of renewal hinges on "context" changes. The majority of previous renewal studies differentiate among contexts by changing several properties of the experimental chamber. In two studies, changes in a single stimulus dimension were used to differentiate among contexts (Podlesnik \& Shahan, 2011 used a flashing versus steady houselight; Kincaid, Lattal, \& Spence, in press, used key colors). Thus, within the renewal literature a variety of procedures are programmed as context changes. Because it is not clear what environmental changes constitute a change in "context," any number of operations may be called a context change. Thus, the number of procedures that may be recast as renewal procedures is as wide as the definition of "context" allows.

Because the recurrence literature includes many variations of renewal, resurgence, and reinstatement, grouping these procedures under a single "renewal" umbrella may unify this diverse literature under a single conceptual framework. The interpretation of resurgence as a renewal effect is only valid, however, if the renewal effect purported to account for resurgence (i.e., ABC renewal) is a reliably demonstrated. It appears that only a single experiment (Bouton et al., 2011) demonstrates $\mathrm{ABC}$ renewal of operant responding. Thus, renewal effects, in particular $\mathrm{ABC}$ and $\mathrm{AAB}$ renewal, invite much more support, particularly if they are to be used as an explanatory framework for other (extensively demonstrated) recurrence phenomena.

If resurgence, reinstatement and renewal are, in fact, variations of a single response recurrence process, then it is perhaps unsurprising that recurrence of ratio strained behavior was observed in all three procedures. Even if renewal can be used to explain resurgence and renewal, however, the procedural distinctions among these effects may still be useful. Differences in the magnitude and reliability of the effects investigated in the present experiments suggest that, even 
if all recurrence phenomena can be attributed to a single response-recurrence process, different recurrence procedures result in different recurrence effects. In this way, even though reinstatement and resurgence procedures may involve changes in context, specifying the details of how such changes are arranged is important because not all context changes may be created equal.

In considering the differences among recurrence procedures, it is perhaps important to consider the salience of the programmed context changes. In a typical renewal procedure, some stimulus changes may be more salient than others. For example, based on the physiological capabilities of the rat, changing the scent of the chamber might constitute a more discriminable context change than changing the flash rate of the houselight, even though changes in both stimuli may be employed in the transition from Context A to Context B. Because these changes are implemented simultaneously, it is impossible to determine the relative contributions of each stimulus change, or what stimulus change is necessary or sufficient to observe the effect. The recurrence procedures used in the present experiments probably employed "context shifts" of varying degrees of salience as well. For example, changing the key color in Experiment 2 may have been a more salient context change than the change in contingency associated with eliminating alternative reinforcement in Experiment 1. However, the renewal procedure was employed in Experiment 2 was an ABA procedure, whereas if resurgence is, in fact, renewal at all, then it is an $\mathrm{ABC}$ renewal procedure. Although no study has directly compared $\mathrm{ABC}$ and ABA renewal effects, ABA renewal is more reliably observed (Bouton et al., 2011). As described above, if context changes are determined by changes in the response-reinforcer contingency (rather than simply the presence/absence of food deliveries), then reinstatement can be interpreted as an $\mathrm{ABC}$ renewal effect. In comparing both $\mathrm{ABC}$-like arrangements in the 
present studies (resurgence and reinstatement), then the deliveries of food in Experiment 1 may have been a more salient context change than the elimination of alternative reinforcement in Experiment 3, which can perhaps partially account for the differences in effect reliability among the two studies.

If stimulus changes accompany contingency changes in the natural environment, it is possible that interactions among recurrence phenomena (whether or not all recurrence phenomena are simply variations of renewal effects) may commonly occur. A recent study by Kincaid, Lattal, and Spence (in press) demonstrated that superimposing an ABA renewal procedure on a resurgence procedure produced a larger resurgence effect than resurgence alone. If those results can be generalized to ratio-strained behavior, then using recurrence procedures in combination might result in greater recurrence of ratio strained behavior. Furthermore, Kincaid et al. found that when a renewal procedure was superimposed on resurgence, the resurgence effect was observed in the first session (in contrast to typical demonstrations of resurgence, in which the effect usually emerges in the second or third session. In this way, combining resurgence and renewal might increase the rapidity of the effect, resulting in quicker response recurrence. Thus, using the procedures investigated here in combination may result in more rapid or greater magnitude recurrence of ratio-strained behavior.

\section{Spontaneous Recurrence of Responding}

A potential limitation of the present experiments was the sometimes-observed spontaneous recurrence of responding after the break point. Two of the present experiments used similar Control Phase procedures (i.e.,session extensions). The rationale for session extensions as controls assumes that little or no responding will occur post-break point. If postbreak point responding occurs in the Control Phase, it is more difficult to attribute the effects of 
the recurrence operation implemented after the break point during test phases (Reinstatement and Renewal Phases).

The possibility of spontaneous recovery of behavior, however, is not unique to the present studies. Spontaneous recovery could account for some of the responding in experiments of any of the three recurrence phenomena. In reinstatement and resurgence experiments, the potential for spontaneous recovery is typically minimized by requiring that a strict extinction criterion is met before moving on to the test phase. This does not appear to be the case with renewal experiments, which have traditionally used a fixed number of extinction sessions, rather than an extinction criterion. The analogous procedure to using a more stringent extinction criterion in the present experiments would be to use a higher break-point criterion. Using a 10min break-point criterion was proposed as an extension for each of the present experiments. However, increasing the break-point criterion might also alter the magnitude of the effect, as in the case of resurgence.

The spontaneous recurrence of responding, when observed, appeared to be a function of training on the PR schedule. Spontaneous recurrence was less likely to be observed after extensive training on the PR schedule. Furthermore, spontaneous recurrence was much less likely in Experiments 2 and 3. It is perhaps important to note that in these experiments the PR schedule was in effect following training on other ratio schedules (VR and FR in Experiments 2 and 3, respectively). Thus, it is possible that training on ratio schedules prior to the PR schedule could have affected this spontaneous recurrence. However, responding on the PR was not systematically different across experiments (with or without FR/VR training) in terms of break points or the temporal distribution of responding within a session. 
Spontaneous recurrence of responding might also be interpreted as a renewal effect, in which the passage of time creates a discriminable shift away from the original reinforcement conditions, resulting in renewed responding. Similar limitations in the demonstration of ABC renewal apply to AAB renewal, particularly, relatively few demonstrations of this effect in operant conditioning. AAB renewal is the least reliable of all renewal effects (Bouton et al., 2011). However, if spontaneous recovery of extinguished behavior is interpreted as a form of $\mathrm{AAB}$ renewal, a similar interpretation could be applied to account for the spontaneous recurrence of responding observed in Experiments 1 and 2, which used session extension control procedures. In both experiments, the prevailing history prior to the session extension was the progressive-ratio procedure, in which a 5-min pause terminated every session. The session extension procedure departs from this procedure by keeping the session active (key lights on, houselight on) with no programmed stimulus change other than the passage of time. If the continuation of the session (in contrast to so many prior sessions in which the session was terminated regularly), constituted a discriminable context shift, then the spontaneous recurrence observed might be interpreted as an $\mathrm{AAB}$ renewal effect. If so, then further investigations of the conditions that amplify and minimize AAB renewal may inform the construction of different control procedures. For example, if AAB renewal is less likely after extensive extinction, then spontaneous recurrence in the session extension may be attenuated by a more stringent breakpoint criterion. This attenuation, however, might be attributed to stimulus generalization (e.g., if a 5-min break-point criterion with a 10-min session extension is more discriminable than a 10min break-point criterion with a 15-min session extension, etc.). Because spontaneous recurrence was observed infrequently and session extensions were of varying durations (as a function of being yoked to test conditions), it would be unwise to draw firm conclusions about spontaneous 
recurrence from the present results alone. Interpreting spontaneous recurrence as renewal, however, does allow for integration of this potential limitation of the experimental design to be accounted for within the same conceptual framework that may account for all of the observed "programmed" response recurrence effects.

\section{Translational Implications}

The finding that several recurrence procedures can be used to recover ratio-strained responding could prove useful for practitioners that encounter ratio strain in behavioral treatment. In the case of systematic schedule thinning, recurrence phenomena could bolster the effectiveness of the "back-up and re-thin" technique by providing a quick burst of responding to contact the enriched reinforcement schedule. In the case of ratio strain encountered with less systematic increases in schedule requirements (e.g., treatment integrity failure resulting in a higher than programmed response requirement), recurrence procedures may serve as techniques to jump-start responding and get the treatment course back on track. It is likely the case that recurrence-like techniques are already at work in some clinical settings (e.g., switching teachers as a renewal procedure, giving "bonus" free tokens as part of a token economy as a reinstatement procedure). The present experiments indicate that systematic application of recurrence phenomena could result in a fruitful line of applied research.

In the translation of these results into clinical situations, many variables warrant consideration. The progressive-ratio schedule provides a model of ratio strain that can be replicated, day after day, in laboratory settings. However, it is unlikely that the procedural regularities of the PR schedule will be precisely replicated in treatment settings. It is much more likely that demanding schedule requirements will vary in their progression with different step sizes, that the progression will be conducted across days (as in schedule thinning), and that 
criteria for implementing a recurrence procedure might vary. It is unclear to what extent these procedural regularities contributed to the observed effects (e.g., would a response thinned for the first time, as in the first session of the PR schedule, be more likely to recur?). Additionally, recurrence of a response with break points in the 100-200 range may look quite different from recurrence of a response that undergoes ratio strain at comparatively low ratios (e.g., a communication response emitted by a nonverbal client).

Nonetheless, the present results indicate that ratio-strained behavior, like extinguished behavior, can recur under a variety of circumstances. Thus, it does not appear to be the case that an organism whose behavior is under strain is incapable of performing the response, but rather that the response is unlikely under the (very specific) present environmental conditions. Changing the conditions, by presenting the previously established reinforcer response independently, returning to context associated with reinforcement, or eliminating reinforcement for another response, can produce recurrence of the ratio-strained response.Conclusions When progressively greater responding is required to obtain reinforcement, behavior eventually becomes strained and reaches a breaking point. The ultimate effect of ratio strain is similar to removing reinforcement completely (i.e., extinction) in that both processes result in the elimination or substantial reduction of responding. The present study underlines the functional similarity of extinction and ratio strain by demonstrating that the same operations that result in recurrence of extinguished behavior also result in recurrence of ratio-strained behavior. This extension is important, because pure extinction is probably far less common than difficult-toobtain reinforcement, outside of laboratory settings.

The response recurrence literature has typically discussed recurrence in the form of relapse of undesirable behavior, including drug addiction and relapse of problem behavior 
following treatment. The present study may have implications for these problems by highlighting that similar procedures are likely to produce relapse, regardless of whether the reinforcer is truly absent from the environment or simply difficult to obtain. However, the present study also has implications for situations in which the recurrence of behavior is desirable, particularly, the persistence of a behavior reinforced during treatment. Best practice requires that for every problem behavior to be eliminated by behavioral treatment, practitioners must also identify an appropriate behavior to replace it. And, if this behavior undergoes ratio strain (e.g., during a schedule thinning procedure), then it is important to understand procedures that can promote recurrence. The present experiments demonstrate that many procedures can cause recurrence of ratio strained behavior, namely, reinstatement, renewal, and resurgence. The present results demonstrate, in sum, that strained behavior (like extinguished behavior) is not irreversibly "broken," but rather, only temporarily eliminated. 


\section{References}

Bouton, M. E. (2004). Context and behavioral processes in extinction. Learning \& Memory, 11(5), 485-494. doi:10.1101/lm.78804

Bouton, M. E., Todd, T. P., Vurbic, D., \& Winterbauer, N. E. (2011). Renewal after the extinction of free operant behavior. Learning \& Behavior, 39(1), 57-67. doi:10.3758/s13420-011-0018-6

Carey, J. P. (1951). Reinstatement of previously learned responses under conditions of extinction: A study of "regression." American Psychologist, 6, 284.

Cleland, B. S., Foster, T. M., \& Temple, W. (2000). Resurgence: The role of extinction. Behavioural processes, 52(2), 117-129. doi:10.1016/S0376-6357(00)00131-5

Epstein, R. (1983). Resurgence of previously reinforced behavior during extinction. Behaviour Analysis Letters, 3(6), 391-397.

Epstein, R. (1985). Extinction-induced resurgence: Preliminary investigations and possible applications. The Psychological Record, 35(2), 143-153.

Ferster, C. B., \& Skinner, B. F. (1957). Schedules of reinforcement. East Norwalk, CT US: Appleton-Century-Crofts. doi:10.1037/10627-000

Fleshler, M., \& Hoffman, H. S. (1962). A progression for generating variable-interval schedules. Journal Of The Experimental Analysis Of Behavior, 5(4), 529-530. doi:10.1901/jeab.1962.5-529

Franks, G. J., \& Lattal, K. A. (1976). Antecedent reinforcement schedule training and operant response reinstatement in rats. Animal Learning \& Behavior, 4(4), 374-378. doi:10.3758/BF03214424 
Gunther, L. M., Denniston, J. C., \& Miller, R. R. (1998). Conducting exposure treatment in multiple contexts can prevent relapse. Behaviour Research And Therapy, 36(1), 75-91. doi:10.1016/S0005-7967(97)10019-5

Hagopian, L. P., Fisher, W. W., \& Legacy, S. M. (1994). Schedule effects of noncontingent reinforcement on attention-maintained destructive behavior in identical quadruplets. Journal Of Applied Behavior Analysis, 27(2), 317-325. doi:10.1901/jaba.1994.27-317

Hodos, W. (1961). Progressive ratio as a measure of reward strength. Science, 134(3483), 943944. doi:10.1126/science.134.3483.943

Hodos, W. (1965). Motivational properties of long durations of rewarding brain stimulation. Journal Of Comparative And Physiological Psychology, 59(2), 219-224. doi:10.1037/h0021818

Hodos, W., \& Kalman, G. (1963). Effects of increment size and reinforcer volume on progressive ratio performance. Journal Of The Experimental Analysis Of Behavior, 6(3), 387-392. doi:10.1901/jeab.1963.6-387

Killeen, P. R., Posadas-Sanchez, D., Johansen, E., \& Thrailkill, E. A. (2009). Progressive ratio schedules of reinforcement. Journal Of Experimental Psychology: Animal Behavior Processes, 35(1), 35-50. doi:10.1037/a0012497

Kincaid, S.L., Lattal, K.A., \& Spence, J. (in press). Super-resurgence: ABA Renewal Increases Resurgence. Behavioral Processes.

Lattal, K. A., \& St. Peter Pipkin, C. (2009). Resurgence of previously reinforced responding: Research and application. The Behavior Analyst Today, 10(2), 254-266.

Leitenberg, H., Rawson, R. A., \& Bath, K. (1970) Reinforcement of competing behavior during extinction. Science, 169, 301-303. 
Lieving, G. A., \& Lattal, K. A. (2003). Recency, Repeatability, and Reinforcer Retrenchment: An Experimental Analysis of Resurgence. Journal Of The Experimental Analysis Of Behavior, 80(2), 217-233. doi:10.1901/jeab.2003.80-217

Nakajima, S., Tanaka, S., Urushihara, K., \& Imada, H. (2000). Renewal of extinguished leverpress responses upon return to the training context. Learning And Motivation, 31(4), 416431. doi:10.1006/1mot.2000.1064

Podlesnik, C. A., \& Shahan, T. A. (2009). Behavioral momentum and relapse of extinguished operant responding. Learning \& Behavior, 37(4), 357-364. doi:10.3758/LB.37.4.357

Rawson, R. A., Leitenberg, H., Mulick, J. A., \& Lefebvre, M. F. (1977). Recovery of extinction responding in rats following discontinuation of reinforcement of alternative behavior: A test of two explanations. Animal Learning and Behavior, 4, 415-420.

Reed, P., \& Morgan, T. A. (2006). Resurgence of response sequences during extinction in rats shows a primacy effect. Journal Of The Experimental Analysis Of Behavior, 86(3), 307315. doi:10.1901/jeab.2006.20-05

Reid, R. L. (1958). The role of the reinforcer as a stimulus. British Journal Of Psychology, 49202-209. doi:10.1111/j.2044-8295.1958.tb00658.

Skinner, B. F. (1948). "Superstition" in the pigeon. Journal of Experimental Psychology, 38, 168-172. doi:10.1037/h0055873

Spradlin, J.E., Girardeau, F.L., \& Hom, G.L. (1966). Stimulus properties of reinforcement during extinction of a free operant response. Journal Of Experimental Child Psychology, 4(4), 369-380. doi:10.1016/0022-0965(66)90038-5 
Stafford, D., \& Branch, M. N. (1998). Effects of step size and break-point criterion on progressive-ratio performance. Journal Of The Experimental Analysis Of Behavior, 70(2), 123-138. doi:10.1901/jeab.1998.70-123

Stewart, W. J. (1975). Progressive reinforcement schedules: A review and evaluation. Australian Journal Of Psychology, 27(1), 9-22. doi:10.1080/00049537508255235

Winterbauer, N. E., \& Bouton, M. E. (2010). Mechanisms of resurgence of an extinguished instrumental behavior. Journal Of Experimental Psychology: Animal Behavior Processes, 36(3), 343-353. doi:10.1037/a0017365 
Table 1.

Experiment 1 Sequence of Conditions and Number of Sessions

\begin{tabular}{lcccc}
\hline & & & Pigeon \\
\cline { 3 - 5 } & Condition & 822 & 2215 & 1189 \\
\hline 1 & PR Baseline & 69 & 41 & 47 \\
2 & YT Reinstatement & 1 & 1 & 1 \\
3 & PR Baseline & 44 & 21 & 40 \\
4 & YT Control & 1 & 1 & 1 \\
5 & PR Baseline & 37 & 42 & 64 \\
6 & FT Reinstatement & 1 & 1 & 1 \\
7 & PR Baseline & 34 & 27 & 41 \\
8 & FT Control & 1 & 1 & 1 \\
\hline
\end{tabular}


Table 2.

Experiment 1 Break Points

\begin{tabular}{|c|c|c|c|c|c|c|c|}
\hline & \multirow[b]{3}{*}{ Condition } & \multicolumn{6}{|c|}{ Pigeon } \\
\hline & & \multicolumn{2}{|c|}{822} & \multicolumn{2}{|c|}{2215} & \multicolumn{2}{|c|}{1189} \\
\hline & & Mean/Test* & Range & Mean/Test & Range & Mean/Test & Range \\
\hline 1 & PR Baseline & 307 & $280-340$ & 139 & $120-160$ & 293 & $260-300$ \\
\hline 2 & YT Reinstatement & 220 & & 110 & & 260 & \\
\hline 3 & PR Baseline & 90 & $60-110$ & 141 & $125-150$ & 308 & $260-340$ \\
\hline 4 & YT Control & 70 & & 150 & & 460 & \\
\hline 5 & PR Baseline & 242 & $210-290$ & 158 & $140-185$ & 157 & $130-220$ \\
\hline 6 & FT Reinstatement & 350 & & 175 & & 170 & \\
\hline 7 & PR Baseline & 240 & $210-330$ & 143 & $125-160$ & 550 & $400-790$ \\
\hline 8 & FT Control & 360 & & 140 & & 650 & \\
\hline
\end{tabular}

Note. Ranges are calculated for the last 6 sessions of the condition.

*For PR baseline, describes mean data for the last 6 sessions of the condition rounded to a whole number; for reinstatement and control sessions, describes data for the PR Phase only for that day. 
Table 3. Experiment 2 Sequence of Conditions and Key Colors

\begin{tabular}{|c|c|c|c|c|c|c|c|}
\hline & \multirow[b]{2}{*}{ Condition } & \multicolumn{2}{|c|}{ Pigeon } & & \multirow[b]{2}{*}{ Condition } & \multicolumn{2}{|c|}{ Pigeon } \\
\hline & & 14167 & 19841 & & & 14507 & 17428 \\
\hline 1 & Context A & Red & Green & 1 & Context A & Red & Green \\
\hline 2 & Context B & Green & Red & 2 & Context B & Green & Red \\
\hline 3 & Renewal & Green, Red & Red, Green & 3 & Renewal & Green, Red & Red, Green \\
\hline 4 & Context A & Red & Green & 4 & Context B & Green & Red \\
\hline 5 & Context B & Green & Red & 5 & Control & Green & Red \\
\hline 6 & Control & Green & Red & & & & \\
\hline 7 & Context A & Red & Green & 6 & Context A & Red & Green \\
\hline 8 & Context B & Green & Red & 7 & Context B & Green & Red \\
\hline 9 & Renewal & Green, Red & Red, Green & 8 & Renewal & Green, Red & Red, Green \\
\hline 10 & Context B* & Green & Red & 9 & Context B* & Green & Red \\
\hline 11 & Control & Green & Red & 10 & Control & Green & Red \\
\hline
\end{tabular}

Note. Colors noted represent main key color. Control key was white in all conditions. All Context A and B conditions consisted of 10 sessions unless otherwise noted.

*Condition consisted of 5 sessions. 
Table 4. Experiment 2 Break Points and Response Rates

\begin{tabular}{|c|c|c|c|c|c|c|c|c|c|c|c|}
\hline & \multirow[b]{3}{*}{ Schedule } & \multicolumn{10}{|c|}{ Pigeon } \\
\hline & & \multicolumn{2}{|c|}{14167} & \multicolumn{2}{|c|}{19841} & & & \multicolumn{2}{|c|}{14507} & \multicolumn{2}{|c|}{17428} \\
\hline & & $\begin{array}{l}\text { Mean/ } \\
\text { Test* }\end{array}$ & Range & $\begin{array}{c}\text { Mean/ } \\
\text { Test }\end{array}$ & Range & & Schedule & $\begin{array}{c}\text { Mean/ } \\
\text { Test }\end{array}$ & Range & $\begin{array}{c}\text { Mean/ } \\
\text { Test }\end{array}$ & Range \\
\hline 1 & VR & 114.85 & $\begin{array}{l}109.76- \\
125.78\end{array}$ & 98.88 & $\begin{array}{l}90.14- \\
112.33\end{array}$ & 1 & VR & 208.46 & $\begin{array}{l}198.45- \\
217.71\end{array}$ & 101.4 & $\begin{array}{l}98.58- \\
107.40\end{array}$ \\
\hline 2 & PR & 214 & $110-290$ & 138 & $100-200$ & 2 & PR & 206 & $170-290$ & 334 & $\begin{array}{l}240- \\
420\end{array}$ \\
\hline 3 & $\mathrm{PR}^{* *}$ & 160 & & 120 & & 3 & $\mathrm{PR}^{* *}$ & 150 & & 180 & \\
\hline 4 & VR & 117.66 & $\begin{array}{l}114.99- \\
122.87\end{array}$ & 113.03 & $\begin{array}{l}90.14- \\
140.90\end{array}$ & 4 & PR & 148 & $130-180$ & 168 & $\begin{array}{l}120- \\
200\end{array}$ \\
\hline 5 & PR & 156 & $140-170$ & 80 & $50-130$ & 5 & $\mathrm{PR}^{* * *}$ & 150 & & 150 & \\
\hline 6 & $\mathrm{PR}^{* * *}$ & 100 & & 60 & & & & & & & \\
\hline 7 & VR & 99.45 & $\begin{array}{l}87.43- \\
105.50\end{array}$ & 94.06 & $\begin{array}{l}41.34- \\
114.47\end{array}$ & 6 & VR & 307.69 & $\begin{array}{c}294.37- \\
316.21\end{array}$ & 77.02 & $\begin{array}{l}54.03- \\
101.37\end{array}$ \\
\hline 8 & PR & 248 & $150-350$ & 135 & $70-150$ & 7 & PR & 290 & $250-340$ & 150 & $\begin{array}{l}110- \\
210\end{array}$ \\
\hline 9 & $\mathrm{PR}^{* *}$ & 140 & & 100 & & 8 & $\mathrm{PR}^{* *}$ & 230 & & 100 & \\
\hline 10 & PR & 134 & $110-180$ & 116 & $100-120$ & 9 & PR & 194 & $150-220$ & 84 & $60-100$ \\
\hline 11 & $\mathrm{PR}^{* * *} *$ & 110 & & 110 & & 10 & $\mathrm{PR} * * *$ & 160 & & 70 & \\
\hline
\end{tabular}

Note. $\mathrm{PR}=$ progressive ratio, $\mathrm{VR}=$ variable ratio. Ranges are calculated for the last 5 sessions of the condition. *For Context A and B conditions, describes mean data (break point or responses/min) for the last 5 sessions of the condition; for renewal and control sessions, describes data from the PR Phase only for that day.

***Renewal session

$* * *$ Control session 
Table 5. Experiment 3 Sequence of Conditions.

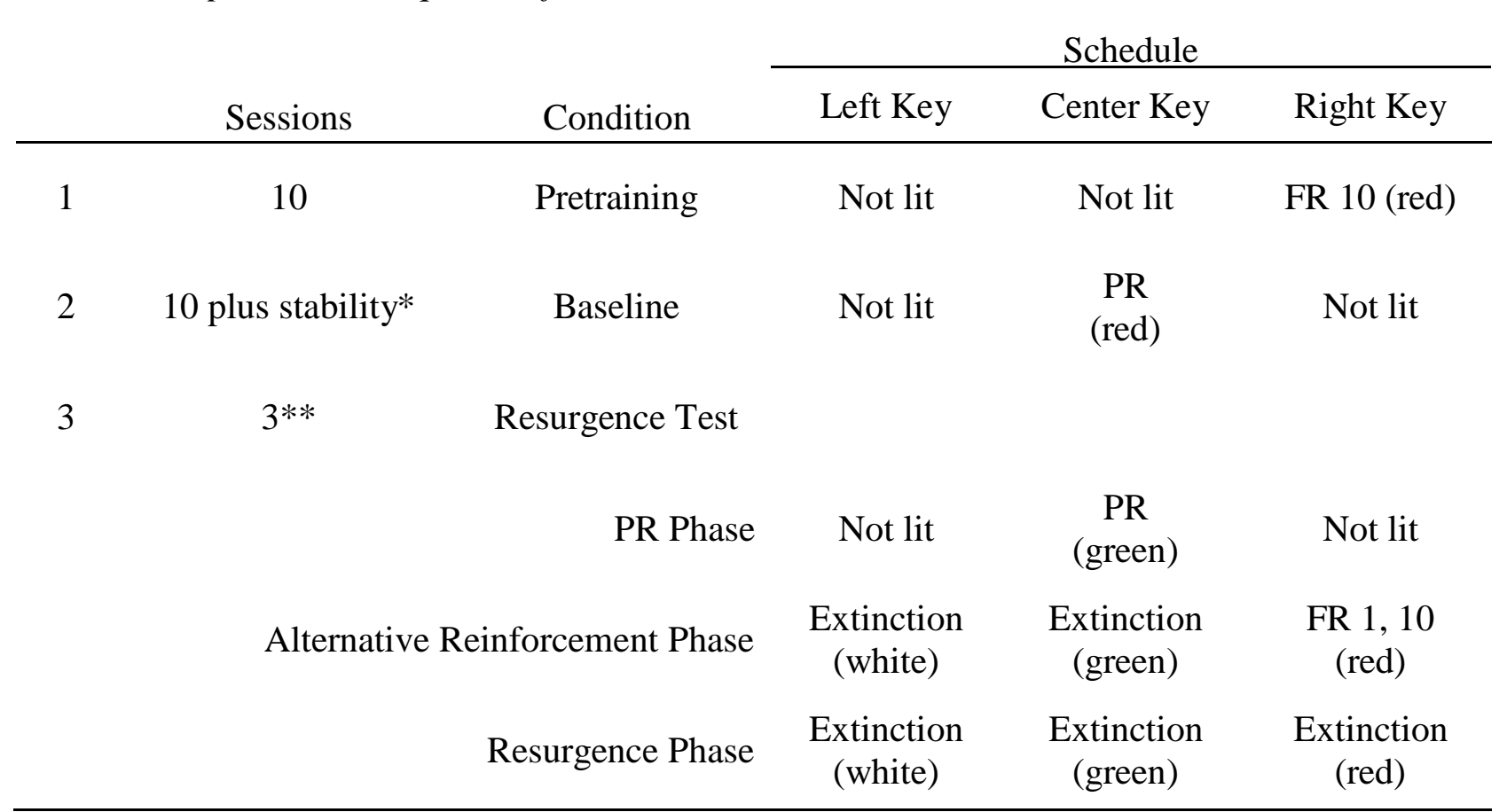

Note. Colors in parentheses represent key color. $\mathrm{PR}=$ progressive ratio, $\mathrm{FR}=$ fixed ratio.

$*$ The baseline condition was in effect for 10, 11, and 15 sessions for 17189, 11718, and 14049 respectively

**Does not include 1 pilot session conducted for 17189 
Table 6. Experiment 3 Response Rates and Break Points

\begin{tabular}{|c|c|c|c|c|c|c|}
\hline & \multicolumn{2}{|c|}{17189} & \multicolumn{2}{|c|}{11718} & \multicolumn{2}{|c|}{14049} \\
\hline Condition & Mean/Test* & Range & Mean/Test & Range & Mean/Test & Range \\
\hline Pretraining & 91.00 & $\begin{array}{c}86.53- \\
96.26\end{array}$ & 69.16 & $\begin{array}{c}63.65- \\
78.00\end{array}$ & 102.49 & $\begin{array}{l}94.52- \\
107.19\end{array}$ \\
\hline Baseline & 256 & $170-350$ & 130 & $70-220$ & 206 & $140-250$ \\
\hline $\begin{array}{c}\text { Resurgence } \\
\text { Test } 1\end{array}$ & 120 & & 190 & & 150 & \\
\hline $\begin{array}{c}\text { Resurgence } \\
\text { Test } 2\end{array}$ & 190 & & 80 & & 210 & \\
\hline $\begin{array}{c}\text { Resurgence } \\
\text { Test } 3\end{array}$ & 150 & & 100 & & 140 & \\
\hline
\end{tabular}

Note. Ranges for baselines are calculated for the last 5 sessions of the condition. Response rates are in responses per min.

*Describes mean data for the last 5 sessions of Pretraining and Baseline conditions; for resurgence tests, describes data for the PR Phase only for that day. 
822
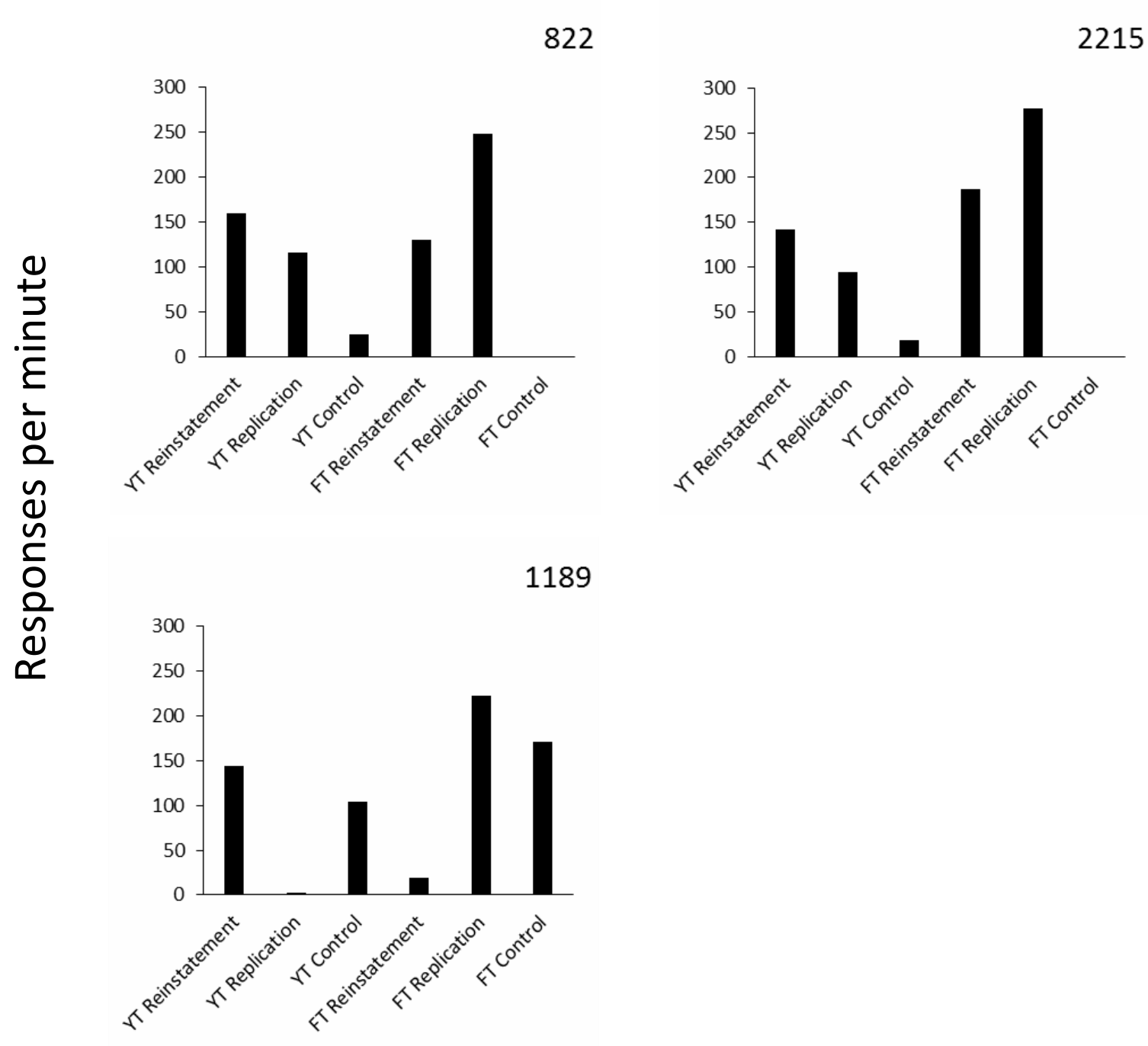

Phase

Figure 1. Overall response rates during reinstatement and control portions of test sessions for all subjects. 
822
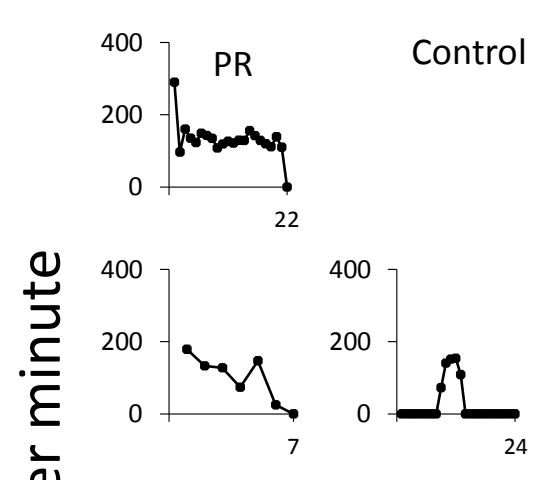

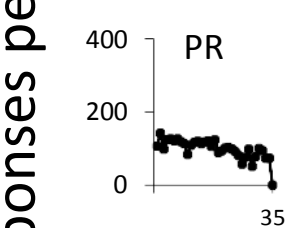

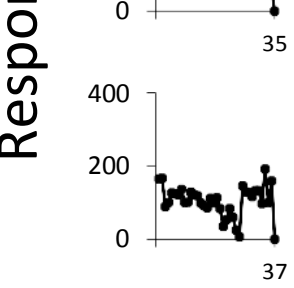

Ratios

Control

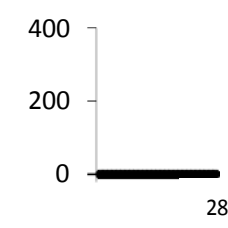

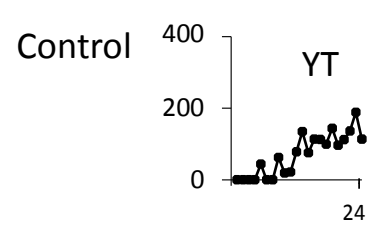
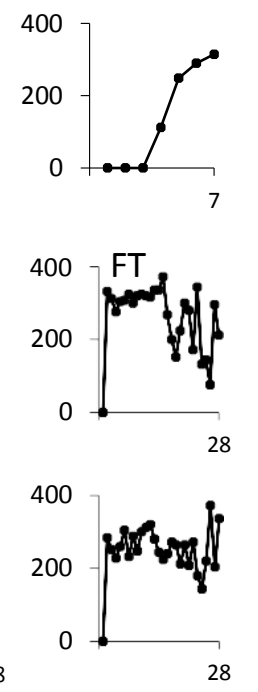

IRIS

Figure 2. Response rates during test sessions. PR and Control identify PR and Control Phases respectively. YT and FT identify Reinstatement Phases with yoked-time or fixed-time food deliveries, respectively. "IRIs" identifies interreinforcer intervals. 


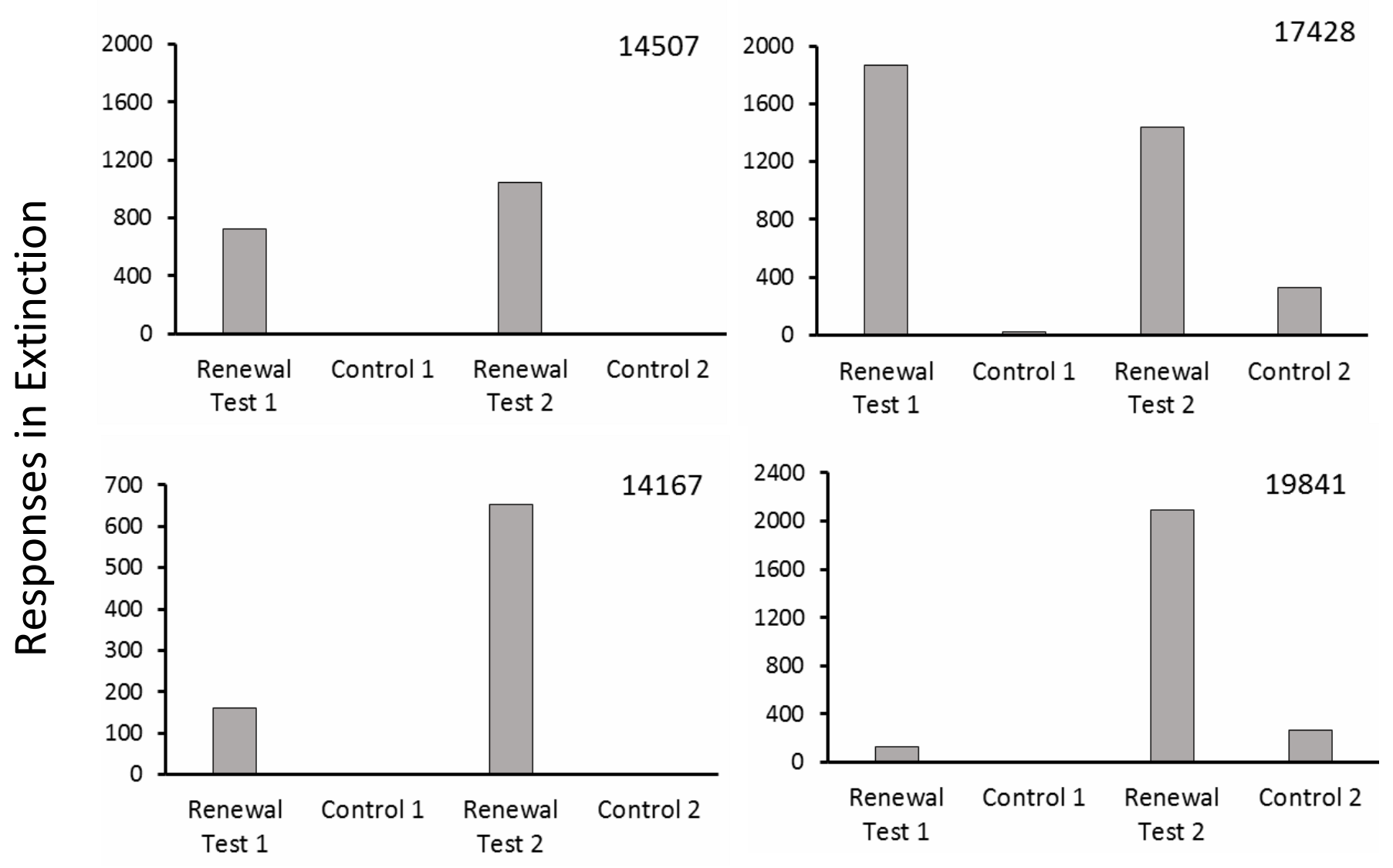

Figure 3. Number of responses during extinction for renewal and control sessions. 


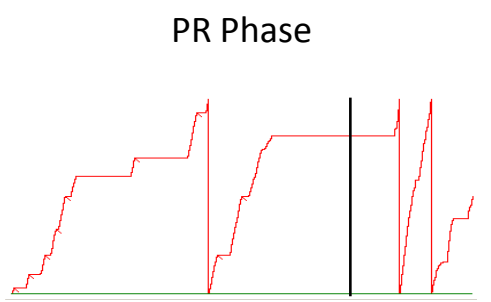

\section{Renewal Phase}
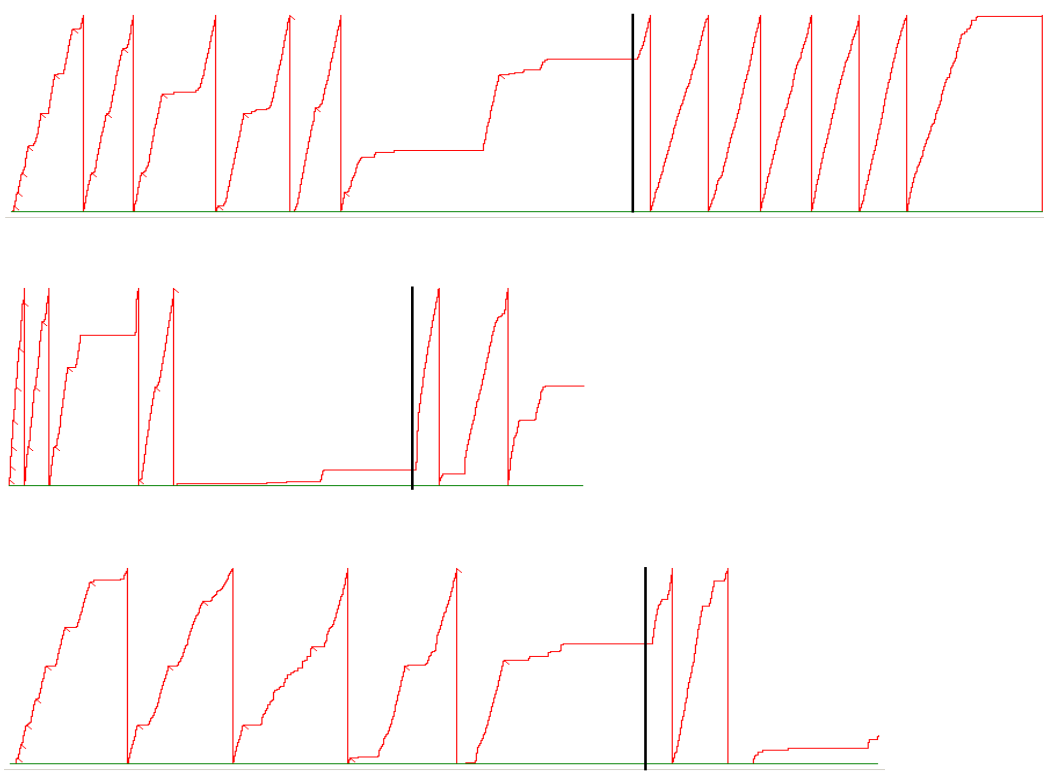

PR Phase
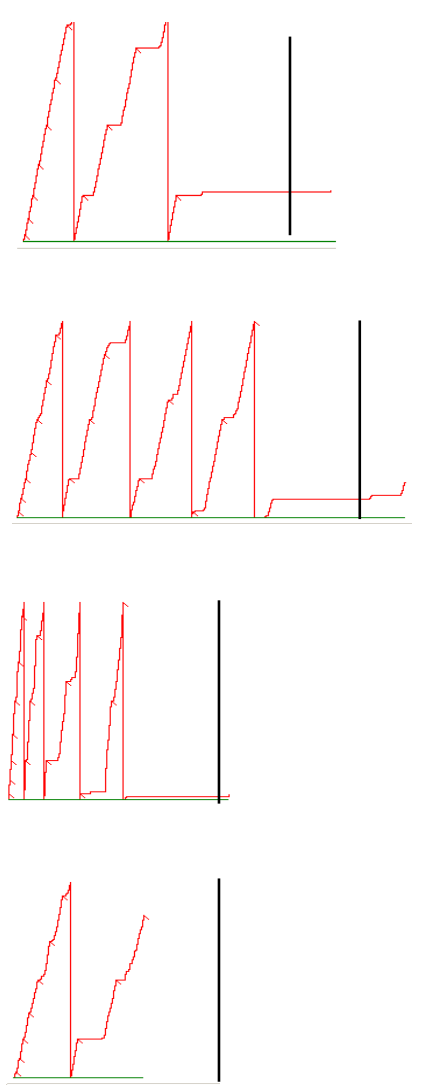

19841

17428

14507

14167

Figure 4. Cumulative records for the first sequence of renewal and control sessions. Solid black vertical line represents the start of the Renewal Phase (left panel) or Control Phase (right panel) 


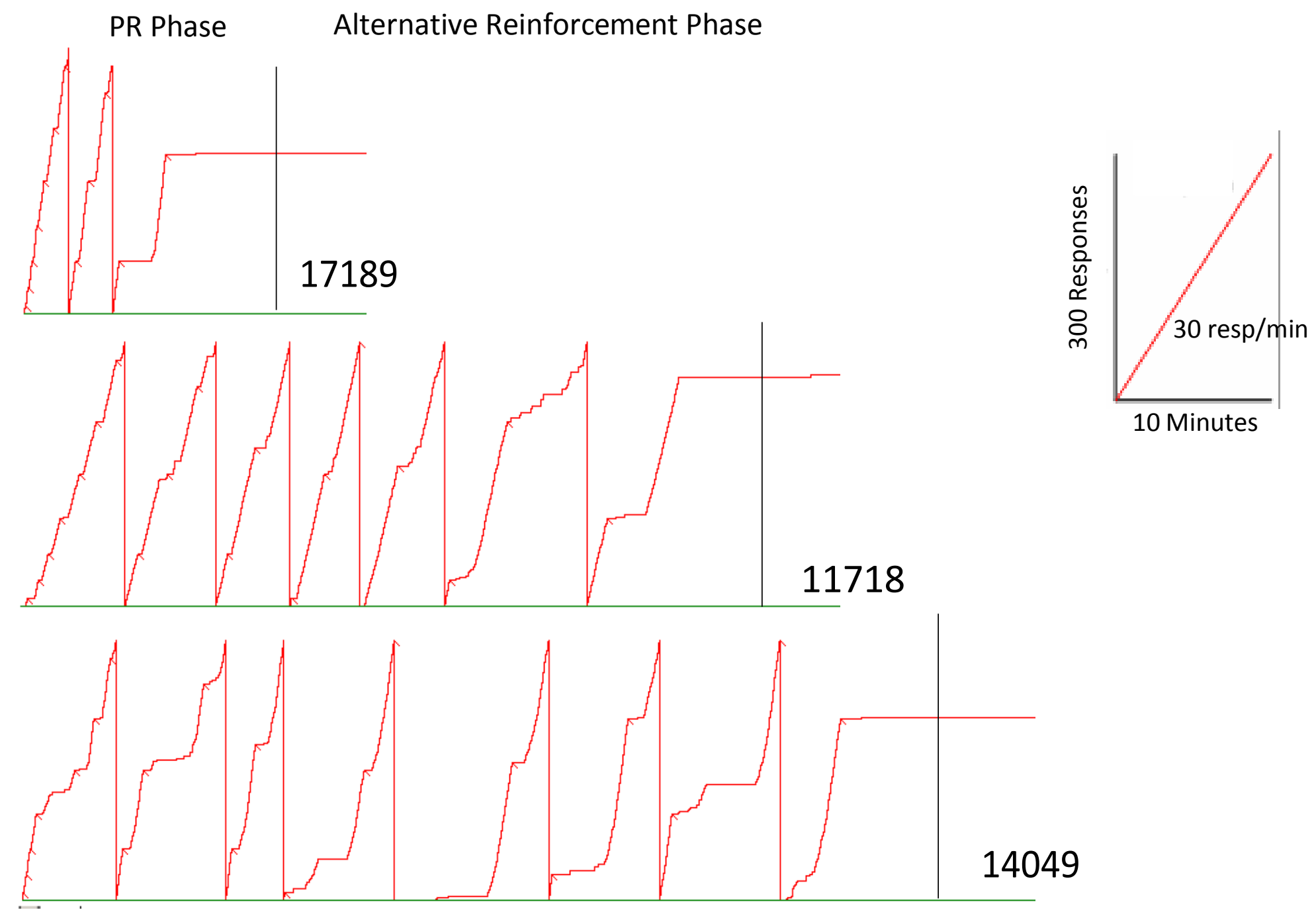

Figure 5. Cumulative records for responding on the PR key for resurgence test sessions 1, 1, and 2 for Pigeons 17189, 11718, and 14049, respectively. Solid line represents the start of the Alternative Reinforcement Phase. 


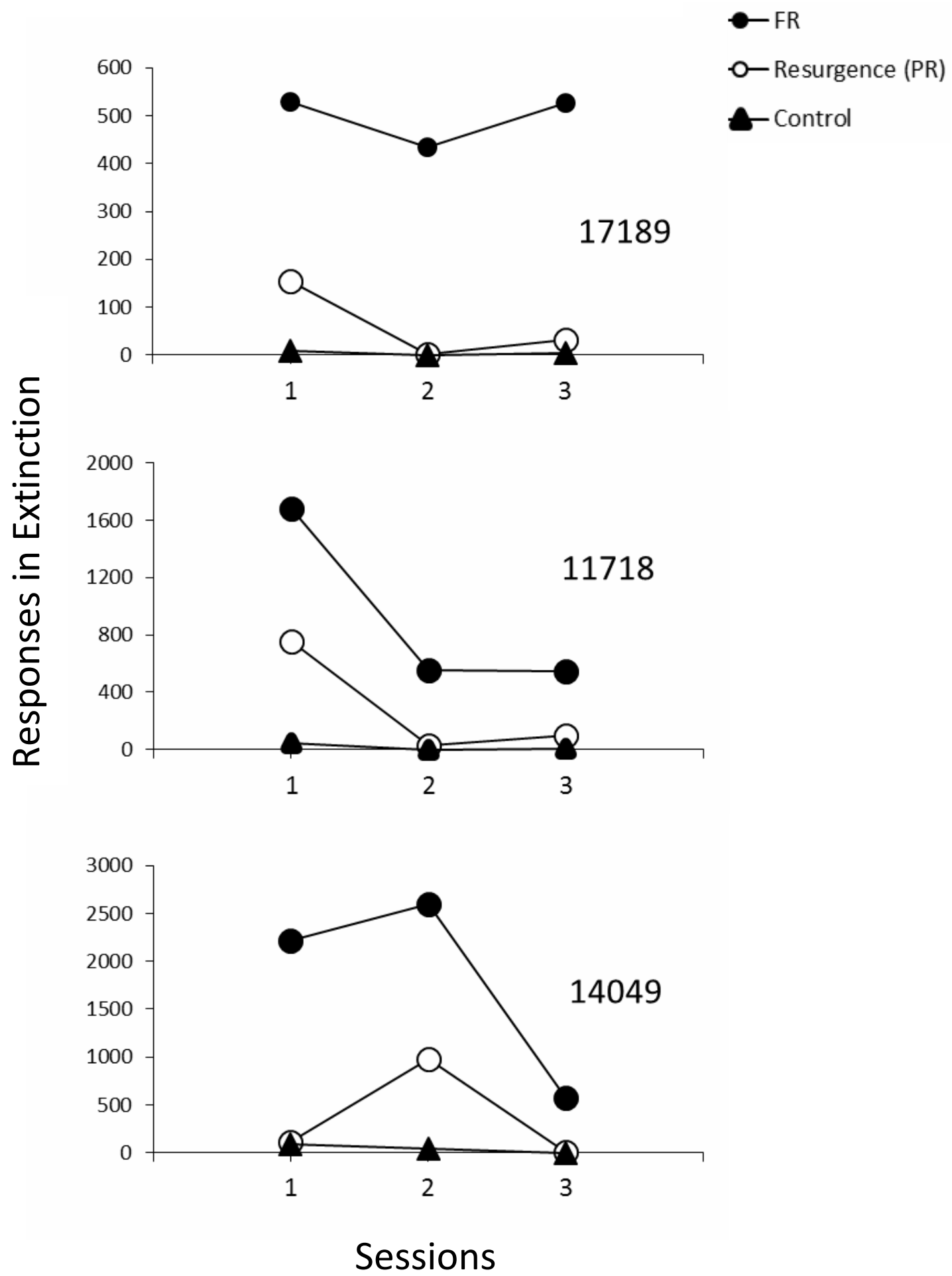

Figure 6. Responses during the Resurgence Phase of successive resurgence test sessions. 

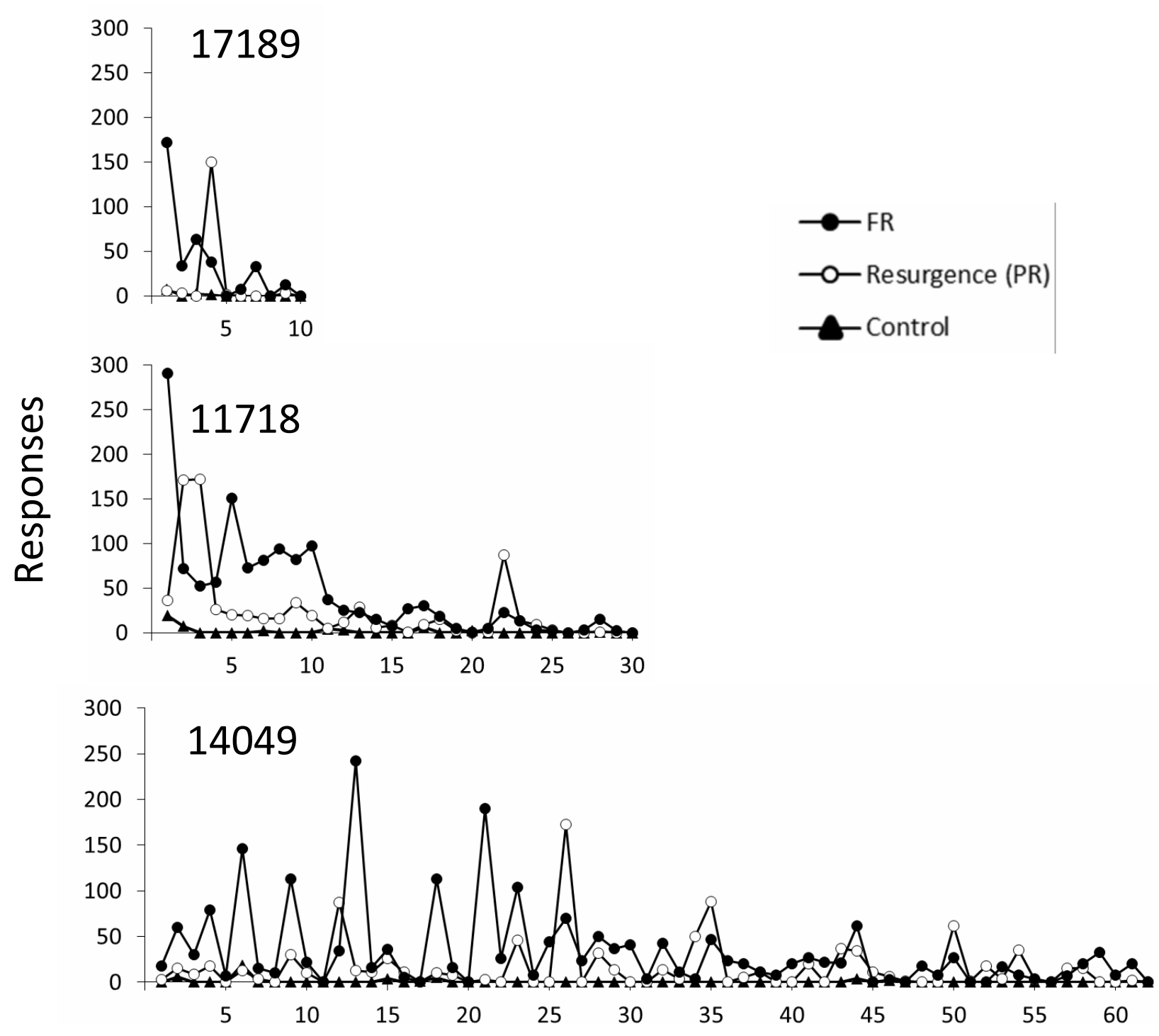

Consecutive 5 min Bins

Figure 7. Responses during the Resurgence phase of resurgence test sessions, summed in 5 min bins, for test sessions 1, 1, and 2 for Pigeons 17189, 11718, and 14049, respectively 